\title{
Asymmetric Patterns of Demand-Supply Mismatch in Real Estate
}

\author{
Gianluca Marcato $^{1} \cdot$ Anupam Nanda $^{2}$
}

Accepted: 7 December 2020 / Published online: 24 March 2021

(C) The Author(s) 2021

\begin{abstract}
As expectations change, we may observe asymmetry in responses of economic agents over various phases of the economic cycles. In this paper, we analyze both demand and supply side information to understand the dynamics of price determination in the real estate market and examine the relationship between expectation parameters and demand-supply mismatch. Our hypothesis builds on the possibility that investors' call for action in terms of their buy/sell decision and adjustment in reservation prices may provide valuable insights into impending demand-supply imbalances in the market. We study several real estate sectors to inform our analysis. The timeframe of our analysis (1995-2010) allows us to observe market dynamics over several economic cycles. We test our hypothesis variously using several measures of market activity within a structural panel VAR framework. Our analysis suggests that investors' attitude may have substantial and statistically significant feedback effects in price determination. These results indicate noticeable asymmetry in responses during the boom, normal and recessionary periods.
\end{abstract}

Keywords Asymmetry · Demand-supply mismatch · Panel VAR model · Real estate

JEL Classifications C53 $\cdot \mathrm{C} 82 \cdot \mathrm{E} 37 \cdot \mathrm{R} 31 \cdot \mathrm{R} 33$

\section{Introduction and Motivation}

A large number of studies in the last couple of decades have made attempt to understand the behavior of economic agents and roles those play in shaping investment

Anupam Nanda

anupam.nanda@manchester.ac.uk

Gianluca Marcato

g.marcato@henley.reading.ac.uk

1 Real Estate \& Planning, University of Reading, Reading, UK

2 Planning \& Environmental Management, University of Manchester, Manchester, UK 
decisions and determining market movements through their collective actions. Such behavior under various economic environments is not straightforward to examine as outcomes may change for different types of agents at different points of economic cycles. While there is a robust theoretical understanding of this process, the empirical evidence is rather thin with mixed outcomes. Therefore, our objective is to examine if buyers and sellers behave differently when the same information is available in the market and their asymmetric responses to returns that reflect both demand- and supplysides trends. We do so by analyzing various phases of upturns and downturns in economic cycles. In this paper, we particularly focus on the real estate sector because it provides some unique features such as market imperfections and precautionary savings that lend support to the rational expectations permanent income hypothesis (Hall 1978). In real estate, volume of investment tends to be lumpy and long-term commitments are required to hold assets i.e. mortgages, debt structures. Therefore, real estate funds hold cash as a cushion in phases of the liquidity to avoid fire sales when property prices are falling. Furthermore, funds do not always spend according to rational expectations and tend to retain cash to create available resources in times when funding is not available. Finally, the distributed lag of past actual income determines a timing mismatch between the investment decision and the deployment of money (i.e. 6-9 months trading period; see Ling et al. 2009).

Consideration of these market features in understanding how sellers and buyers respond variously to changes in economic condition is particularly important. Therefore, using several proxies derived from a survey of institutional investors, we explore (and find evidence for) demand-supply mismatches and the existence of feedback loops, which follow asymmetric patterns over the market cycle. We study several real estate sectors over 1995-2010 and test our hypotheses variously using within a structural panel VAR framework and analyzing impulse response functions.

We have organized the rest of the paper as follows: firstly, we discuss relevant literature in detail, and we identify testable hypotheses within the literature; we then describe the data and empirical framework used in this study in "Data Description" and "Empirical Framework" sections. Finally, we present an in-depth analysis of the empirical evidence, robustness checks and provide conclusions in the last two sections.

\section{Relevant Literature}

The primary stock market and investment psychology literature revolve around a few strands of theoretical frameworks and empirical tests. The notion of rationality in asset pricing and assumptions under the Capital Asset Pricing Model (CAPM) are frequently challenged, and Hirshleifer (2001) provides a comprehensive survey of the literature. Market scenarios may influence the association of expectations and returns, as reported in Chiu et al. (2014), who use index and financial exchange-traded funds (ETFs) to find an asymmetric effect on equity liquidity and investor trading behavior during the subprime crisis period. Kumar and Lee (2006) examine whether the buy-sell activities of retail investors contain a common directional component. In their clientele-based framework, different investor groups operate within different natural "habitats", i.e. have a preference for certain groups of stocks. As a result of such preference-based trading behavior, the returns may also reflect underlying expectations. Specifically, the authors test the 
hypothesis that "... if the buy-sell patterns of retail investors do not move in lock-step with overall market movements, assets in market segments dominated by these investors could be characterized by pricing anomalies that are associated with their trading activities".

Within real estate, the RERC LLC ${ }^{1}$ reports investor attitudes each quarter. Using a survey of institutional investors, Ling (2005) finds that the consensus opinions on investment conditions contained in RERC survey are not useful in forecasting subsequent return performance. Similarly, using the RERC survey and data from Korpacz PriceWaterhouse Coopers, Clayton et al. (2009) examine the extent to which fundamentals and investor attitudes explain the time-series variation in national-level cap rates. They find evidence that investor attitudes impact pricing, even after controlling for changes in expected rental growth, equity risk premiums, T-bond yields, and lagged adjustments from long-run equilibrium. Marcato and Nanda (2016) test several real estate indexes and find that they contain valuable information that can help predict changes in real estate returns. Nanda (2007) analyzes predictive ability of a survey-based sentiment index in the residential market. Das et al. (2015) looks at sentiment-induced behavior in the REIT market.

Specifically for residential markets, the marketing time (or 'time on market', i.e. TOM) has been shown to be negatively related to price movements, possibly indicating that investor's attitudes are more optimistic in periods when properties are transacted quickly. Benefield et al. (2014) present an overview of the literature focused on the relationship between TOM and real estate prices, while Sirmans et al. (2010) provide a meta-analysis of the key studies. For commercial real estate, we find very few studies and they mainly focus on the seller's perspective - e.g. Lin and Vandell (2007) - even though the buyer's perspective (market entry) also matters. Moreover, other studies suggest the need to better define the measurement of time on market for both residential (Benefield and Hardin 2015) and commercial markets (McNamara 1998 and Bond et al. 2004).

More recently, some studies have used data from online search engines to measure market sentiment. Online search data may contain information about what economic agents are interested in (see for example, Choi and Varian 2012 et al.). Hohenstatt and Kaesbauer (2014) have shown that the sub-categories in the Google Trends tool are more suitable than the broader search volume index.

In two recent studies, Heinig and Nanda (2018) and Heinig et al. (2020) present a simple test for the potential of different market indicators to improve a basic cap rate model. Using commercial real estate data for London West End, the results indicate a considerable improvement in model accuracy. Finally, van Dijk et al. (2018) use more refined internet search data, i.e. the number of clicks on properties listed online - to study price and liquidity dynamics of the Dutch housing market. They construct a market tightness indicator from internet search behavior and find this measure to represent a good predictor of future changes in both prices and liquidity.

The above literature review suggests the possibility of an association between investors' expectations and market returns. ${ }^{2}$ Such an association may reveal asymmetric behaviour depending on the market structure, circumstances and economic cycles. These possibilities motivate our testable hypotheses, as described in the following section.

\footnotetext{
${ }^{1}$ RERC, LLC (formerly known as Real Estate Research Corporation), is now a wholly-owned subsidiary of Situs. The survey, now known as the Situs RERC Real Estate Report

${ }^{2}$ There is a more extensive literature on sentiment in mainstream economics and finance. Here we focus on the most relevant aspects of literature.
} 


\section{Theoretical Underpinning and Testable Hypotheses}

We test several theoretical hypotheses building on the interactions and bargaining behavior of buyers and sellers in the market. Buyers and sellers shape their behavior based on 'signal processing' of the information set at a given point in time. The 'signal processing' may vary from buyers to sellers, and it may depend on the phase of the market cycle in which they operate. The adjustment of buyers' and sellers' reservation prices may reflect such behaviors, which may also show noticeable temporal variation. Hence, the underlying assumption behind our theoretical hypotheses is that economic agents' expectations inform their actions, which, in turn, lead to the potential formation of a reservation price gap or a demand-supply mismatch. These situations are observable in phases when buyers are not willing to pay high prices (in down markets), or sellers are not willing to accept low offers (in up markets), or buyers are willing to pay higher prices in up markets. In these circumstances, market liquidity may change along with the trading activities and very few transactions may occur. On the other hand, when the buyers are willing to purchase at high prices (in rising markets), and sellers are willing to accept low offers (in falling markets), the demand-supply mismatch might be narrower. As a result, the likelihood of an agreement between the offer and asking prices increase, leading to a larger number of successful completions.

Based on the above research issues, we put forward two plausible reasons behind the asymmetric patterns in agents' responses during different phases of a market cycle:

- A Shift in Bargaining Abilities: Depending upon the phase in the cycle, the bargaining power of sellers and buyers changes. Boom times typically reflect sellers' markets, tilting the balance of bargaining power to the sellers' side with significantly more demand than supply. On the contrary, recessionary periods are often buyers' market with more bargaining power on buyers' side with low demand and sellers willing to accept lower prices in order to clear inventory.

- Long-Run Investment Commitment and Maturity Mismatch: Real estate as an investment sector is notoriously thin in terms of liquidity and it takes significant time on the market to sell properties. Typically, real estate investors cannot sell properties quickly as they are locked in a long-term commitment. As a result, the price increase during boom times may be faster than in the normal market conditions. During the boom times, buyers may need to increase their reservation prices faster if they want to access a rising market or else, they risk being outbid by other buyers. Note, we define a normal market as one in which demand and supply conditions are relatively in balance. On the other hand, during market downturns, prices may not follow the same speed of adjustment. Although it is a buyers' market, long-term commitment may cause price stickiness due to maturity mismatch. In these market settings, sellers may need to resort to non-price discounts to clear inventories and cut losses.

The above theoretical underpinnings require a suitable empirical framework. We argue that the computable difference-in-difference estimator discussed in Fisher et al. (2003) is an appropriate methodology for investigating the research questions in this paper. They note that a transaction is observed when the reservation prices of the buyer is higher than the seller's reservation prices. Hence, assuming that the transaction price is 
the mid-point of the bid-ask prices, and using a probit model with transacted and nontransacted properties, they derive two separate indices for demand and supply. The distance between these two indices and the actual transaction price is symmetrical. However, its size varies over time. We follow a similar approach. Specifically, we compute a proxy for the demand-supply mismatch by taking the difference between the demand and supply indices relative to the price index level at that time. We interpret the difference as the Reservation Price Gap $(R P G)$ i.e. it represents the gap between the reservation prices of buyers and sellers:

Reservation Price Gap $(R P G)=$ Return on Supply Index (Rets)-Return on Demand Index (Retd)

Figure 1 shows the conceptual background of this definition of the demand-supply mismatch. The buyer and seller's distributions overlap to show the extent of transaction activities. The graph at the top shows a market state (A) with an overlap of the two frequency distributions of reservation prices less pronounced than in the market state (B) which is reflected in the graph below. It then results in the state (A) having a fewer number of transactions. The state (A) occurs due to only a small number of buyers and sellers being matched compared to that in the state (B) where the frequency distributions of the buyers and sellers reservation prices overlap to a greater extent (the bottom graph).

The difference-in-differences design of the estimator enables us to identify and study the feedback effects that are associated with a time trend and those reflecting the asymmetry between two time periods. Similar to Fisher et al. (2003) and van Dijk et al. (2018), we reformulate Eq. (1) as follows:

$$
\begin{gathered}
R P G_{D I D}=\left(P_{t+1}{ }^{S}-P_{t}^{S}\right)-\left(P_{t+1}^{B}-P_{t}^{B}\right) \\
=\left(P_{t+1}{ }^{S}-P_{t+1}{ }^{B}\right)-\left(P_{t}^{S}-P_{t}^{B}\right)
\end{gathered}
$$

where $R P G_{D I D}$ represents the reservation price gap computed as the difference between the change in sellers' reservation prices from time t to $\mathrm{t}+1$ (respectively $P_{t}^{S}$ and $P_{t+l} S$ ) and the change in buyers' reservation prices from time $t$ to $t+1$ (respectively $P_{t}^{B}$ and $\left.P_{t+I^{B}}\right)$.

It is important to note that RPG in Eq. (2) is not a simple difference between reservation prices of the buyers and sellers. It is rather designed to capture difference in reservation prices in two time periods ( $t$ and $t+1)$. Intuitively, several theoretical relationships can emerge, which are empirically testable. The buyers and sellers' demand-supply schedules are presented in Fig. 2, and through horizontal summation, a two-agent market equilibrium occurs. Note that in the presence of many economic agents, the kinks smooth out.

In Panel A, we report the original demand and supply indices, alongside the frequency distributions of the buyers and sellers' reservation prices that determine the reservation price $(R P G)$ "AB". The point X represents the equilibrium price at the intersection of demand and supply, which is the basis for computing return indices. Panel B shows a symmetric response of buyers/sellers where the reservation price gap 


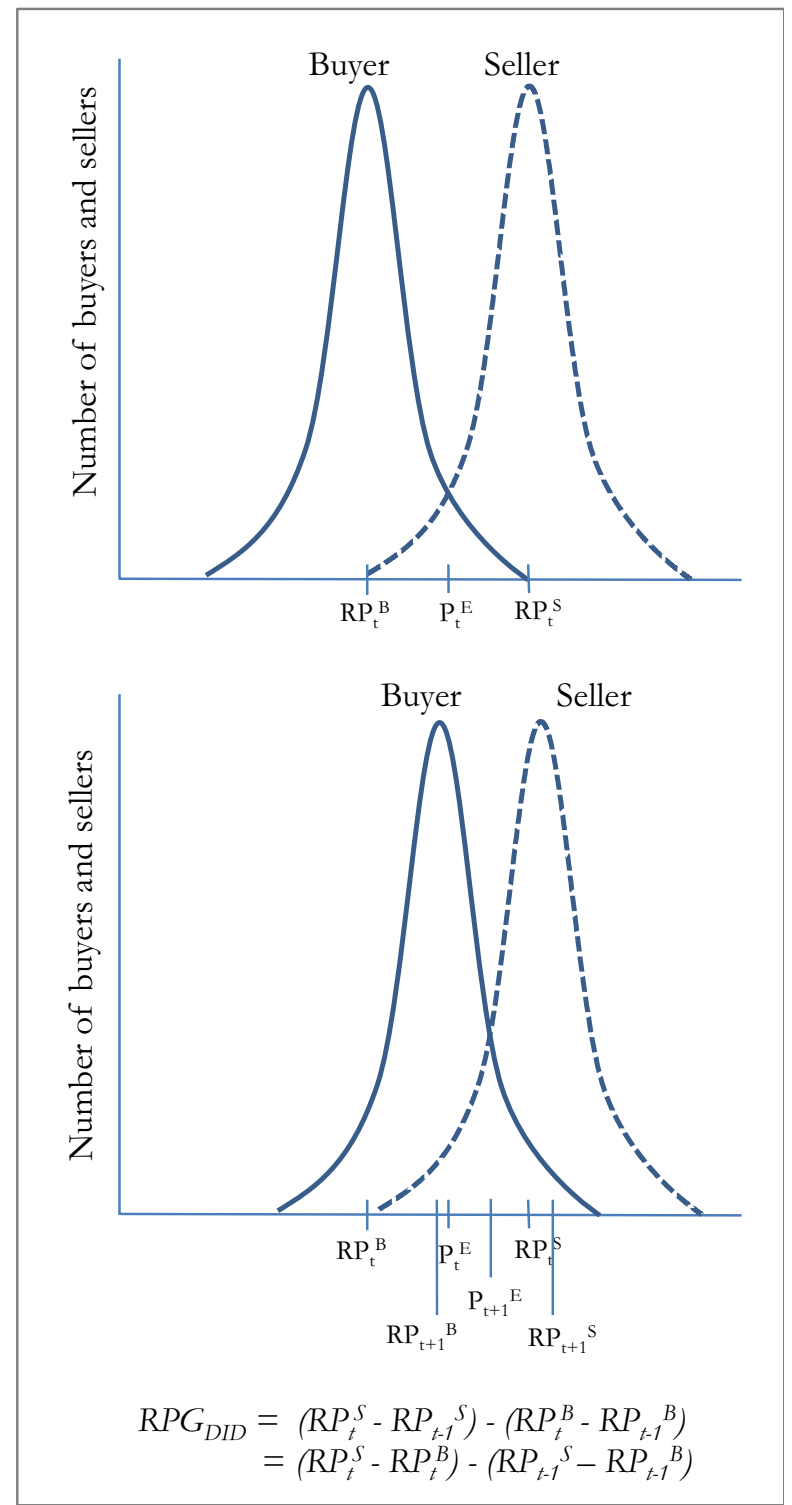

Fig. 1 Reservation Price Gap. Note: the top graph shows a wider gap between buyers and sellers' reservation prices. As a result, the two probability distributions overlap less and we should record a lower level of transactions because there is less matching between buyers and sellers in the market

remains unchanged at "AB". Finally, the remaining two graphs on the right-hand side show the asymmetric response to a buyer's (top) and a sellers' (bottom) position, where the reservation price gap narrows as the two distributions move closer to each other. In particular, Panel C shows a situation when buyers move first towards the sellers' reservation price points by raising their reservation prices and, the $R P G$ measure changes from "AB" to "CB". Panel D instead shows a move by the sellers' towards 

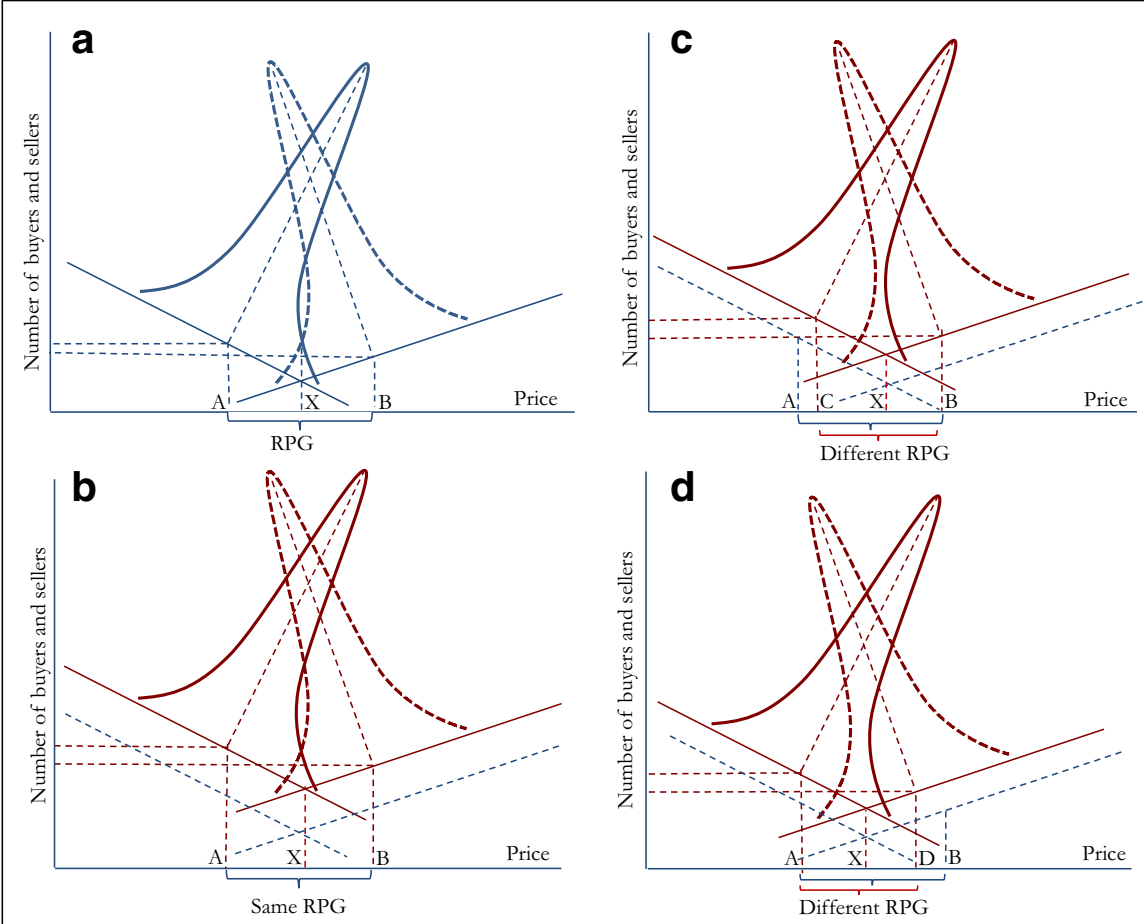

Fig. 2 Dynamics of Asymmetry. Note: These graphs represent symmetric (left) and asymmetric (right) responses to a buyer and seller's move. The initial price reservation gap (RPG) is set at AB in Panel a. Panel b shows a symmetric response that leads to no change in RPG (still at AB). However, an asymmetric response may cause a reduction in the RPG measure to either CB in the case of a buyer's move (Panel c), or AD in case of a seller's move (Panel d)

the buyers' reservation prices. If they reduce their reservation prices, the $R P G$ measure changes from "AB" to "AD".

Referring to the research issues discussed earlier, we identify the main data sources that can allow us to compute the DID estimator discussed above. A detailed data description is provided in a separate section later. We use information on four indicators i.e. marketing time, buy-sell recommendations, investment conditions and distressed sale. Specifically, we build the following testable hypotheses based on these measurable market indicators.

Hypothesis I. Time on market shorter in up market and longer in down cycles:

During an up-cycle, there are more potential buyers than sellers. The time on market therefore tends to be shorter and it can reflect the underlying mismatch between demand and supply. It is likely that buyers adjust their reservation prices upwards at a rate faster than the sellers' prices. As a result, the RPG measure (as defined in equation-2) would narrow. In contrary, during the down cycles, the dynamics change. Sellers generally prefer non-price discounts to a price reduction to avoid the possibility of price-cutting wars. Avoidance of price-cutting is essential, as price reductions would 
signal weaknesses, and the buyers could further exploit the situation by bargaining harder for deeper price discounts that could lead to successive price cuts and a downward price spiral. Therefore, at least initially during the down cycle, the seller's reservation price does not change or changes at a slow rate. Buyers, observing more availability, may start reducing their reservation prices. As a result, the price gap widens. However, as the recession deepens or lingers with increasing marketing time, the sellers would also need to offer more aggressive price discounts to offload inventories which may lead to sharper and frequent price reductions. The downward spiraling of prices would entail a narrowing RPG.

Hypothesis II. More buy than sell recommendations in up market and more sell than buy recommendations in down market:

More buy than sell recommendations will lead to more demand. A higher level of investment demand will cause the demand curve to shift upwards or to the right with respect to the supply curve. It is also likely that rising demand will entail a faster upward adjustment to buyers' reservation prices compared to that of the sellers. Therefore, in up cycles, this could eventually lead to a tighter RPG. On the other hand, there is a possibility of more sell than buy recommendations in down-cycles, leading to changes in RPG.

Hypothesis III. Investment conditions improve in down markets:

A change in the perception of investment conditions in a rising market may lead to adjustments in reservation prices by buyers and sellers. However, the adjustment process can differ for buyers and sellers. Assume that investment conditions worsen after a period of significant growth. Buyers may embed this signal more readily and carefully than sellers because they may want to trade only when there is more assurance that prices will not decline, especially after a long phase of growth. On the other hand, sellers may be willing to wait longer before revising their reservation prices downwards even if they stand to lose by not exiting immediately. It may be due to significant accumulation of capital gains which can allow them to withstand further price cuts. The net effect on RPG may depend on relative bargaining power. On the other hand, during a down cycle, if investment conditions improve, a cautious optimism may prevail among buyers and with sellers adjusting their reservation prices upward, it may lead to a widening RPG.

Hypothesis IV. Prevalence of distressed sales during the down cycles:

Recessions and market slumps are opportune times for portfolio building at low prices. The so-called 'vulture' investors exploit such possibilities through aggressive buying of distressed assets. During down cycles, price expectations tend to be revised frequently and faster than other times and sellers are often more profoundly affected in these scenarios. The prevalence of distressed sales would actually increase demand for investment assets in a down cycle, where otherwise there are not many buyers. Sellers' reservation prices may need to fall faster to close transactions as demand reservation prices keep falling. Therefore, the existence 

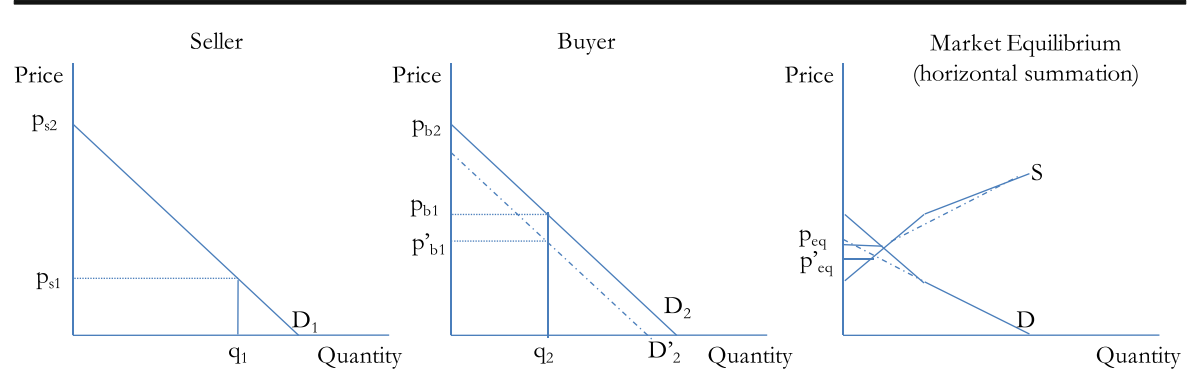

Scenario-I: (a) Time to market increases. (b) More buy than sell recommendations in down market. (c) Investment condition improves in down market.
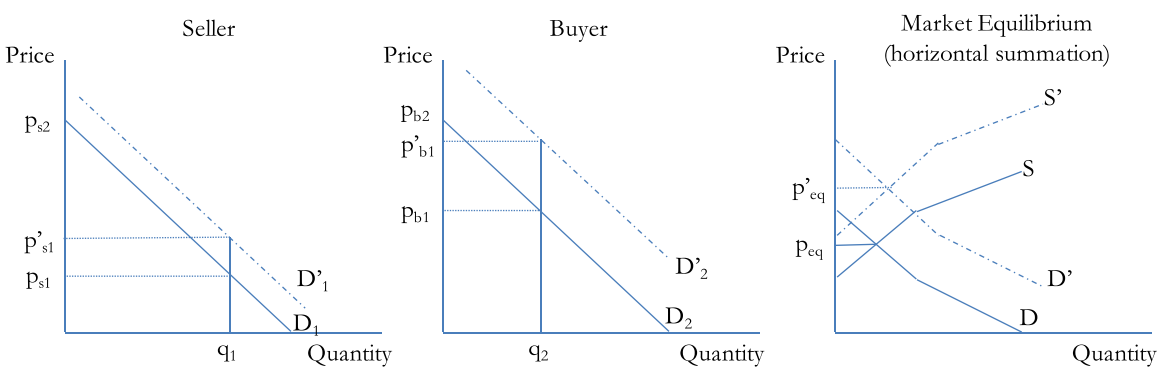

Scenario-II: (a) Time to market decreases. (b) More buy than sell recommendations in up market.

(c) Investment condition improves in up market.

Fig. 3 Indicators of demand-supply mismatch. Note: The figure represents the change in demand and supply due to three main proxies of market expectations (investment conditions, marketing time and buy vs sell recommendations)

of vulture investors in a crisis tightens the RPG, compared to a situation without these vulture investors.

The dynamics of market equilibrium would crucially depend on how buyers and sellers move based on their own perspectives and market conditions. In aggregate, we can visualize the changes in market equilibrium conditions by the gradual movements (price-related) and shifts (non-price determinants) in demand and supply curves. As an example, Fig. 3 presents a visualization of the dynamics of market equilibrium. Making direct reference to our key hypotheses, we show changes in relation to the market indicators.

Figure 3 presents two possibilities: the upper panel shows adjustments due to favorable bargaining position of buyers in down markets and the lower panel shows adjustments due to favorable bargaining position of buyers in up markets.

\section{- $\quad$ Time on Market Shorter in Up Market and longer in Down Cycles}

In a rising market, buyers may raise their reservation prices faster than sellers because of their eagerness to be invested rather than holding onto cash. On the contrary, in a falling market, we should see the reservation price gap decrease because buyers are reducing prices faster than sellers.

- More Buy than Sell Recommendations in Up Market and More Sell than Buy Recommendations in Down Market 
Buyers are more directly targeted by these recommendations. Therefore, a much faster upward revision in buyers' reservation prices than in sellers' reservation prices can be expected. As a result, the RPG measure narrows.

\section{- Investment Conditions Improve in Down Markets}

If investment conditions improve in terms of broader economic and financial factors in down markets, liquidity may recover, and hence we may find a higher volume of transactions. Increasing transaction volumes may encourage sellers to act as pricesetters as they see higher than the average number of prospective buyers per sale item or property. This may result in widening RPG.

Next, we test the above-mentioned hypotheses with a detailed empirical analysis based on a rich set of information on the US real estate market. We use a panel estimation framework with four key sub-sectors (office, retail, industrial and the other) for the variables of interest (demand and supply returns, RPG and proxies of market expectations).

\section{Data Description}

Our analysis includes a set of indicators capturing market sentiment and standard economic data. Specifically, we analyze several indicators from the Real Estate Research Corporation (RERC) survey, along with indicators reflecting financial distress. Our return or performance variables are based on the MIT/CRE CREDL TransactionsBased Index (TBI) for non-residential real estate sector. The US-based firm Situs RERC surveys hundreds of experts each quarter to gauge commercial real estate investment trends and return expectations. Notably, they collect institutional investment information for top 48 metros and 11 major property types in the US.

From the RERC survey, we use information for marketing time, buy-sell recommendations and investment conditions. The sample period is 1995Q1 through 2010Q4. Our data for demand and supply indices ends in 2010, as the data providers no longer produce these indices. For further discussion on the transition from these indices to transaction-based indices provided by NCREIF (NTBI), ${ }^{3}$ please refer to the white paper by Geltner (2011). Even if we are not able to capture the latest information, we still believe that the real estate market provides a suitable and robust laboratory to test the research hypotheses that are relevant to any periods. Moreover, the time period is sufficiently long and enables us to observe and infer from the experiences of multiple economic cycles, including the Global Financial Crisis. As far as we are aware, no other sectors provide both an adequate setting for testing the rational expectation permanent income hypothesis and the availability of demand and supply indices.

A detailed definition of the variables is provided in Table 1. As there are no direct measures of demand and supply for real estate markets, we have decided to use the transaction-based indices (TBI) created by CREDL (the Centre of Real Estate Data

\footnotetext{
${ }^{3}$ NCREIF is the National Council of Real Estate Investment Fiduciaries and collects, processes and provides commercial real estate indices for its members and to the benefit of the market. The new NTBI methodology can be found here: https://www.ncreif.org/data-products/tbi/.
} 
Table 1 Variable description

\begin{tabular}{|c|c|c|}
\hline Variable & Description & Source \\
\hline \multicolumn{3}{|c|}{ Real state returns } \\
\hline Ret & Transaction-Based Index (TBI) return & MIT/CRE Commercial Real Estate Data Laboratory \\
\hline Retd & Transaction-Based Demand Index return & MIT/CRE Commercial Real Estate Data Laboratory \\
\hline Rets & Transaction-Based Supply Index return & MIT/CRE Commercial Real Estate Data Laboratory \\
\hline \multicolumn{3}{|c|}{ Economic/financial variables } \\
\hline GDPR & Real Gross Domestic Product growth rate & Thomson Reuters Datastream \\
\hline CPI & Consumer Price Index growth rate & Thomson Reuters Datastream \\
\hline INT10Y & 10- year Treasury bond yield & Thomson Reuters Datastream \\
\hline INT03M & 3-month Treasury bill rate & Thomson Reuters Datastream \\
\hline \multicolumn{3}{|l|}{ Other variables } \\
\hline TOM & Time to Market (to sell a property) & Situs RERC (Real Estate Research Corporation) \\
\hline BUYSELL & Ratio of buy vs. sell responses & Situs RERC (Real Estate Research Corporation) \\
\hline INVCOND & Surveyed market investment conditions & Situs RERC (Real Estate Research Corporation) \\
\hline DELIQ & Delinquency on commercial real estate loans & Federal Reserve Economic Data (FRED), St. Louis Fed \\
\hline DELIQ_RE & Delinquency on overall real estate loans & Federal Reserve Economic Data (FRED), St. Louis Fed \\
\hline
\end{tabular}

This table reports the main sources and description of the variables used in our study. Particularly, TOM represents the marketing time required to sell a property, buy-sell computes a ratio of the recommendation to either buy or sell indicating the outlook on the next 6-12 months; invcond reflects the expectations of investment conditions in the market over next 6-12 months; DELIQ and DELIQ_RE represent the delinquency rate of respectively commercial real estate loans (excluding farmland) and overall real estate loans (including housing)

Laboratory at MIT) as proxies for demand-supply imbalances. ${ }^{4}$ Along with the TBI for real estate assets, CREDL also publishes a constant-liquidity price index capturing two dimensions of market functionality from the asset owners' perspective, price and expected time-on-the-market, which are then combined into a single dimension, liquidity-adjusted price. This measure represents price movements, with holding the expected time on the market constant, i.e. liquidity. Mainly, the demand index reflects buyers' responses, thus driving the constant-liquidity values. The supply index represents prices required to maintain a constant 'ease of selling'. As reported above, these indices have been computed and made available only until the end of 2010.

As the sample period covers 1995Q1 to 2010Q4, we acknowledge the need for extending the analysis to a period beyond 2010 in order to include more up to date information. The MIT Property Price Dynamics Platform ${ }^{5}$ now publishes regional supply and demand indices from 2005. The period 2005 to 2010 represents the overlapping period of our sample with the newly constructed demand and supply indices provided by van Dijk et al. (2018, unpublished working paper). Contrary to Fisher et al. (2007) in terms of the methodology, the new indices are estimated only using repeat sales (i.e. properties transacted at least twice during the sample period). Therefore, considering the economic shock during this period due to the Global

\footnotetext{
${ }^{4}$ The MIT/CRE CREDL Transactions-Based Index are available at - http://web.mit.edu/cre/research/credl/tbi. html

${ }^{5}$ Source: http://pricedynamicsplatform.mit.edu/analytics.html.
} 
Financial Crisis, the characteristics of properties transacted more than once may differ from the ones that were transacted less often. The underlying sample of transacted properties in the MIT/CREDL indices that we use in our paper is larger than the one used by the newly constructed repeat-sales version. Furthermore, the new repeat sales indices are computed by city and then area (East, West, Midwest and South). To obtain a national average and to compare it with the MIT/CRE CREDL indices, we compute an equally weighted average of the RPG measure of the four areas. We then explore the possibility of extending the data series with these new indices, bearing in mind that these indices are regional and based on a different set of data. Firstly, three out of four property types are represented as industrial sector is not covered by the new series. Moreover, we correlate the new RPG measure derived from the new demand and supply indexes with the one used in our analysis. Similar to the focus of our paper, we compare up and down cycles and we find that our measure based on the MIT/CREDL indices is highly correlated (almost 83\%) with the RPG using new indices based on repeat-sales method. Moreover, our sample covers a long period, and it allows us to explore up and down cycles not only around the most recent crisis in 2008 but also in the 1990s. Therefore, we do not think, our analysis suffers significantly from the lack of recent data.

Situs RERC tracks investment conditions, marketing time and buy/sell/hold recommendations across 11 property types and publish a quarterly Real Estate Report. This dataset is aggregated at the national level from the RERC's quarterly institutional survey responses obtained from real estate institutional players, such as REITs, pension funds, insurance companies, banks, and opportunity funds. ${ }^{6}$ Particularly, investment conditions represent a ranking of current investment desirability (rated on a scale of 1 to 10, with 1 being low/weak and 10 being high/strong) of 11 property types for the US institutional real estate market. According to RERC, the scale refers to the factors affecting the market at the current time that an investor would need to consider before investing in the property. Such factors include availability of capital for investing in properties, price of properties, availability of properties for purchase and expected returns. The measure of investor attitude captures the ratio of investors with optimistic view about investment opportunities relative to those who show a less optimistic market outlook. For a further description and use of the RERC data, see Ling et al. (2014) for an assessment of investor sentiment and limits to arbitrage in private real estate markets.

Furthermore, the marketing time (or, time on market i.e. TOM) represents the time needed to market a property in a specific sector. It is measured in average number of months and defined over the period between offering of a property for sale and securing a bona fide buyer. In our context, TOM is used as a measure of investor attitude. A higher TOM reveals a difficulty in finding a counterparty for the deal (as it takes more time to market the asset), while a reduction in TOM would reflect a buoyant market where it is easier to find counterparties and close transactions.

In addition, buy/sell/hold recommendations represent a rating that indicates whether it is a good time to buy, sell, or hold commercial real estate within a mixed-asset portfolio context. The ratings are on a scale of 1 to 10 , with 1 being a 'poor' time to

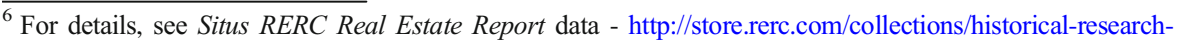
data
} 

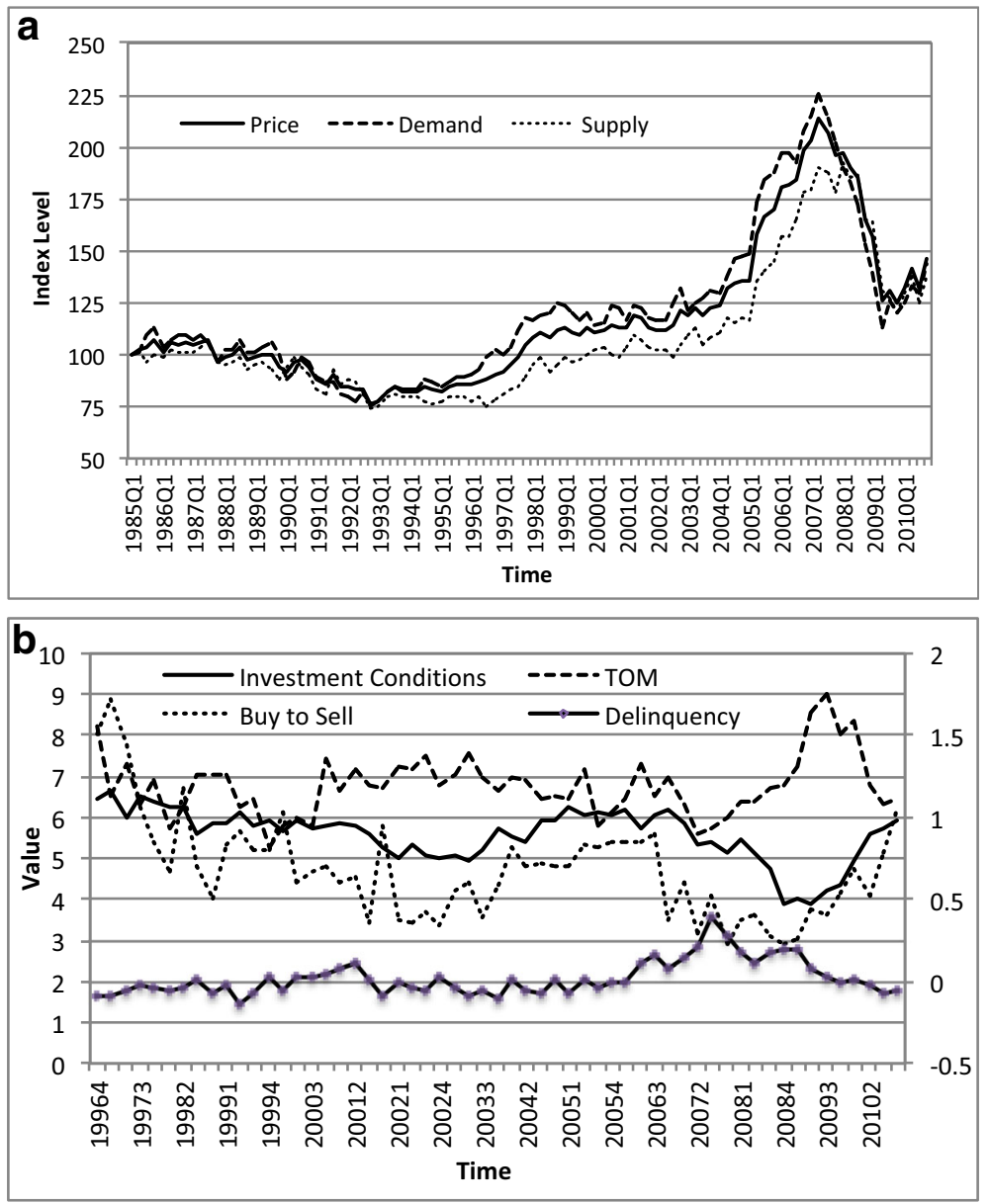

Fig. 4 Transaction Based Indexes and Delinquency Rate. Panel a: Transaction Based Indexes, Panel b: Investor Attitudes and Delinquency Rate. Note: The graph reports demand and supply indexes, as well as an index for the equilibrium price. The difference between supply and demand indexes reveals the reservation price gap we observe in the market. The change in this measure represents the key variable used in our study. Note: Investment Conditions (LHS), Time on Market (i.e. TOM, LHS) and Buy to Sell recommendations (RHS) are taken from the RERC survey. The delinquency rate of commercial real estate loans (RHS) is obtained from the database FRED provided by the Federal Reserve Bank of St. Louis

buy, sell, or hold, and 10 is an 'excellent' time to buy, sell, or hold. In our analysis, we use a metric with the number of buy recommendation minus the number of sell recommendations to capture the direction as well as the extent of opposing views. A higher value of buy-to-sell recommendations (driven by an increase in buy intentions relatively to sell intentions) indicates an improvement in market conditions, while a reduction in the ratio would reflect worsening conditions and weakening of investment intentions.

Finally, with respect to financial distress, we use seasonally adjusted delinquency rates of commercial real estate (excluding farmland) loans booked in domestic offices of all commercial banks (DELIQ). This measure is a part of the 
database FRED provided by the Federal Reserve Bank of St. Louis. ${ }^{7}$ As a robustness check, we also use delinquency rates of the overall real estate market (including housing) from the same source (DELIQ_RE), and our results are consistent.

Figure 4 presents price index and changes in the level of financial distress over time. In Panel A, varying nature of the gap between demand and supply indices shows potential demand-supply mismatch. Note that the mismatch starts to exacerbate towards the end of the recession in the early 1990s until 1996. The extent of mismatch fluctuated for a few years, with a slight drop at the beginning of the 2000s i.e. the dotcom bust, and it then recovered to the highest levels of the end 1990s and also, starting from 2003 until the beginning of 2008 economic downturn. Interestingly, the mismatch peaked in the third quarter of 2005, suggesting that some signals of an impending economic downturn could have been picked up by looking at the fundamentals behind the price escalation.

Panel B shows our key variables of interest i.e. indicators for investor attitudes and the delinquency rate. Particularly, we see that investment conditions started to deteriorate at the beginning of 2007 until the third quarter of 2009. Correspondingly, the average perceived time to execute transactions (TOM) started to rise from about less than 6 months in 2007 to a peak of more than 9 months towards the end of 2009. Buy to sell recommendations show a similar pattern to other two measures of investor attitude. Finally, the level of financial distress in commercial real estate remained low throughout the period until the financial crisis.

\section{Empirical Framework}

Our empirical framework for testing the causal relationships between returns and demand-supply mismatch is based on the Auto-regressive Distributed Lag method $A R D L(p, q)$. We pool observations from three real estate sub-sectors over time to estimate a panel VAR model with no prior assumptions on potential causality. A structural panel VAR representation (see Wooldridge 2010) is represented as follows:

$$
\begin{aligned}
& y_{i t}=a_{10}+\beta_{11} x_{i t}+\varphi_{11} y_{i t-1}+\varphi_{12} x_{i t-1}+v_{y i t} \\
& x_{i t}=a_{20}+\beta_{21} y_{i t}+\varphi_{21} y_{i t-1}+\varphi_{22} x_{i t-1}+v_{y i t}
\end{aligned}
$$

where $i$ refers to the industry sector and $t$ refers to the quarters. In Eqs. (3a) and (3b), both $\left\{y_{i t}\right\}$ and $\left\{x_{i t}\right\}$ are assumed to be stationary, and the error terms are white-noise disturbances. We use a number of standard tests to choose an appropriate lag length (e.g. Akaike Information Criteria (AIC), Bayesian Information Criteria (BIC)).

The assumption of stationarity in Eqs. $3 \mathrm{a}$ and $3 \mathrm{~b}$ can be easily violated in most economic relationships. Specifically, we test for the existence of error correction processes, where the short-run change in a variable is associated with both the change in a determinant variable and the difference between the variables in the previous

\footnotetext{
$\overline{{ }^{7} \text { Source: https://fred.stlouisfed.org/. }}$
} 
period, i.e. the lagged disequilibrium. To validate this approach, we conduct detailed tests for time series properties of the variables. In particular, we conduct the standard tests of stationarity and co-integration using Augmented Dickey-Fuller (ADF) and Phillips-Peron (PP) tests, as well as Levin et al. (2002) test for common unit roots as we deal with panel data. As all endogenous variables (e.g. RPG and the four investors' attitude proxies) are stationary, i.e. of order $\mathrm{I}(0)$, we choose a structural vector autoregressive (VAR) over a vector error correction model (VECM).

Full development of the VAR system of equations is as follows:

$$
\begin{aligned}
& \operatorname{Ret}_{i t}=\alpha+\sum_{j=1}^{n} \beta_{j} \operatorname{Ret}_{i, t-j}+\sum_{j=1}^{n} \gamma_{j} \text { Att }_{i, t-j}+\sum_{k=1}^{p} \lambda_{k} \text { Control }_{k, t}+\varepsilon_{i t}^{\text {Ret }} \\
& \text { Att }_{i t}=\alpha+\sum_{j=1}^{n} \beta_{j} \operatorname{Ret}_{i, t-j}+\sum_{j=1}^{n} \gamma_{j} \text { Att }_{i, t-j}+\sum_{k=1}^{p} \lambda_{k} \text { Control }_{k, t}+\varepsilon_{i t}^{\text {Att }}
\end{aligned}
$$

Where $\operatorname{Ret}_{i, t-j}$ are the total returns in market equilibrium (i.e. considering markerclearing prices in arm's length transactions). $A t t_{i, t-j}$ is the proxy for market attitude. Control $_{k}$ refers to the macroeconomic and financial control variables such as real GDP growth, inflation, interest rates, term structure and credit spread.

Furthermore, we test for the differences between buyer's and seller's responses to changes in the market conditions. We use three alternative pricing measures for the test, namely the return price gap $\left(R P G_{i, t-j}\right)$, demand-side and supply-side returns $\left(\operatorname{Retd}_{i, t-j}\right.$ and Rets $_{i, t-j}$ respectively). These are noted in columns 1 to 3 in tables within the main results section. For parsimony, we report the estimates from the first equation in the VAR system for each pricing measure as follows:

$$
\begin{gathered}
R_{i t}=\alpha+\sum_{j=1}^{n} \beta_{j} \operatorname{RPG}_{i, t-j}+\sum_{j=1}^{n} \gamma_{j} \text { Att }_{i, t-j}+\sum_{k=1}^{p} \lambda_{k} \text { Control }_{k, t}+\varepsilon_{i t}^{R P G} \\
\operatorname{Retd}_{i t}=\alpha+\sum_{j=1}^{n} \beta_{j} \operatorname{Ret}_{i, t-j}+\sum_{j=1}^{n} \gamma_{j} \text { Att }_{i, t-j}+\sum_{k=1}^{p} \lambda_{k} \text { Control }_{k, t}+\varepsilon_{i t}^{\text {Retd }} \\
\text { Rets }_{i t}=\alpha+\sum_{j=1}^{n} \beta_{j} \operatorname{Rets}_{i, t-j}+\sum_{j=1}^{n} \gamma_{j} \text { Att }_{i, t-j}+\sum_{k=1}^{p} \lambda_{k} \text { Control }_{k, t}+\varepsilon_{i t}^{\text {Rets }}
\end{gathered}
$$

In particular, we use four different proxies for market attitude $\left(A t t_{i, t-j}\right)$ : buy-sell recommendations $\left(B U Y S E L L_{i t}\right)$, marketing time $\left(T O M_{i t}\right)$, investment conditions $\left(I N V C O N D_{i t}\right)$ and delinquency rates of commercial real estate $\left(D E L I Q_{i t}\right)$. Therefore, each previous equations is estimated for all four market attitude measures.

Therefore, we first report the estimates of the following equations for buy-sell recommendations:

$$
\begin{aligned}
& R P G_{i t}=\alpha+\sum_{j=1}^{n} \beta_{j} R P G_{i, t-j}+\sum_{j=1}^{n} \gamma_{j} \text { BUYSELL }_{i, t-j}+\sum_{k=1}^{p} \lambda_{k} \operatorname{Control}_{k}+\varepsilon_{i t}^{R P G} \text { (6a) } \\
& \operatorname{Retd}_{i t}=\alpha+\sum_{j=1}^{n} \beta_{j} \operatorname{Retd}_{i, t-j}+\sum_{j=1}^{n} \gamma_{j} \text { BUYSELL }_{i, t-j}+\sum_{k=1}^{p} \lambda_{k} \operatorname{Control}_{k}+\varepsilon_{i t}^{\operatorname{Retd}(6 \mathrm{~b})}
\end{aligned}
$$




$$
\text { Rets }_{i t}=\alpha+\sum_{j=1}^{n} \beta_{j} \text { Rets }_{i, t-j}+\sum_{j=1}^{n} \gamma_{j} \text { BUYSELL }_{i, t-j}+\sum_{k=1}^{p} \lambda_{k} \operatorname{Control}_{k}+\varepsilon_{i t}^{\text {Rets }}(6 \mathrm{c})
$$

We then report the estimates of the following equations for testing the hypothesis on marketing time:

$$
R P G_{i t}=\alpha+\sum_{j=1}^{n} \beta_{j} R P G_{i, t-j}+\sum_{j=1}^{n} \gamma_{j} \text { marketingtime }_{i, t-j}+\sum_{k=1}^{p} \lambda_{k} \text { Control }_{k}+\varepsilon_{i t}^{R P G}
$$

$$
\begin{aligned}
\operatorname{Retd}_{i t}= & \alpha+\sum_{j=1}^{n} \beta_{\mathrm{j}} \operatorname{Retd}_{i, t-j}+\sum_{j=1}^{n} \gamma_{j} \text { marketingtime }_{i, t-j}+\sum_{k=1}^{p} \lambda_{k} \text { Control }_{k} \\
& +\varepsilon_{i t}^{\text {Retd }}
\end{aligned}
$$

$$
\operatorname{Rets}_{i t}=\alpha+\sum_{j=1}^{n} \beta_{j} \operatorname{Rets}_{i, t-j}+\sum_{j=1}^{n} \gamma_{j} \text { marketingtime }_{i, t-j}+\sum_{k=1}^{p} \lambda_{k} \text { Control }_{k}+\varepsilon_{i t}^{\text {Rets }}
$$

Next, we report the estimates of the following equations to examine the investment conditions:

$$
\begin{aligned}
& R_{P} G_{i t}=\alpha+\sum_{j=1}^{n} \beta_{j} \operatorname{RPG}_{i, t-j}+\sum_{j=1}^{n} \gamma_{j} \text { invcond }_{i, t-j}+\sum_{k=1}^{p} \lambda_{k} \operatorname{Control}_{k}+\varepsilon_{i t}^{R P G}(8 \mathrm{a}) \\
& \operatorname{Retd}_{i t}=\alpha+\sum_{j=1}^{n} \beta_{j} \operatorname{Retd}_{i, t-j}+\sum_{j=1}^{n} \gamma_{j} \text { invcond }_{i, t-j}+\sum_{k=1}^{p} \lambda_{k} \operatorname{Control}_{k}+\varepsilon_{i t}^{\text {Retd }}(8 \mathrm{~b}) \\
& \operatorname{Rets}_{i t}=\alpha+\sum_{j=1}^{n} \beta_{j} \operatorname{Rets}_{i, t-j}+\sum_{j=1}^{n} \gamma_{j} \text { invcond }_{i, t-j}+\sum_{k=1}^{p} \lambda_{k} \operatorname{Control}_{k}+\varepsilon_{i t}^{\text {Rets }}(8 \mathrm{c})
\end{aligned}
$$

Finally, we report the estimates of the following equations to analyze distressed market scenario using the delinquency rate:

$$
\begin{aligned}
& R P G_{i t}=\alpha+\sum_{j=1}^{n} \beta_{j} R P G_{i, t-j}+\sum_{j=1}^{n} \gamma_{j} \text { deliq }_{i, t-j}+\sum_{k=1}^{p} \lambda_{k} \text { Control }_{k}+\varepsilon_{i t}^{R P G} \\
& \operatorname{Retd}_{i t}=\alpha+\sum_{j=1}^{n} \beta_{j} \operatorname{Retd}_{i, t-j}+\sum_{j=1}^{n} \gamma_{\mathrm{j}} \operatorname{deliq}_{i, t-j}+\sum_{k=1}^{p} \lambda_{k} \text { Control }_{k}+\varepsilon_{i t}^{\text {Retd }} \\
& \operatorname{Rets}_{i t}=\alpha+\sum_{j=1}^{n} \beta_{j} \operatorname{Rets}_{i, t-j}+\sum_{j=1}^{n} \gamma_{j} \text { deliq }_{i, t-j}+\sum_{k=1}^{p} \lambda_{k} \text { Control }_{k}+\varepsilon_{i t}^{\text {Rets }}
\end{aligned}
$$


A key concern in using the proxy variables for attitude is the possibility of presence of omitted variable bias. The proxy variables contain two components - one that depends on the fundamental return drivers because the measures tend to be highly correlated with the standard economic measures and those may also correlate with the unobservables. The second component may capture the element that does not correlate with the standard measures of economic fundamentals. Therefore, we use a two-stage procedure, where we orthogonalize all proxies against a set of standard macroeconomic indicators in step 1. We then use the residuals of the first stage equation of the panel VARs in step 2 to derive the element driven by the investor's attitude and test its effects on pricing and demand-supply mismatch. This is suggested by Ling et al. (2015) and Marcato and Nanda (2016). For this purpose, we use several common macroeconomic variables such as real GDP growth rate $\left(G D P R_{t}\right)$, changes in the consumer price index $\left(\right.$ infl $\left._{t}\right)$, the real interest rate (rint $t, 10$-year treasury bond yield net of inflation), the term spread $\left(T S_{t}\right.$, computed as the difference between 10-year Treasury bond yield and 3month T-bill rate) and the credit spread $\left(\mathrm{CredSpr}_{t}\right.$, yield difference between AAA- and BBB- rated bonds).

$$
A t t_{t}=\alpha+\beta_{1} \text { GDPR }_{t}+\beta_{2} \text { infl }_{t}+\beta_{3} \text { rint }_{t}+\beta_{4} T S_{t}+\beta_{5} \text { CredSpr }_{t}+\varepsilon_{t}
$$

Where $A t t_{t}$ is with the proxy for four measures presented above i.e. investment conditions, marketing time, buy/hold/sell recommendations and financial distress. Macroeconomic variables are also included as the exogenous variables within the panel VAR framework in stage 2 . Note that, they are perfectly orthogonal to other attitudedriven elements obtained as residuals from the estimation of the model in stage 1 and reported in the main VAR systems as $A t t_{i, t-j}$.

Finally, as buyers' and sellers' behavior may vary over the cycle, we interact down and up cycle dummies with market attitude indicators. For the down cycles, we identify recession periods according to the definition adopted by the National Bureau of Economic Research (NBER): the down cycle dummy takes a value of 1 when a sector return reflects negative change for two consecutive quarters. Similarly, the upcycle dummy takes a value equal to 1 when a market return reflects positive rolling annual growth over and above average +1 standard deviation. We find that down and up cycles cover around $23 \%$ and $25 \%$ of the overall sample period respectively (please also refer to Table 2 for descriptive statistics). For the remaining times, markets are considered 'stable' or 'normal'.

\section{Results and Analysis}

\section{Main Results}

We first test for stationarity with $\mathrm{ADF}$ and PP tests and perform standard Granger causality tests. These tests confirm stationarity of our RPG measure and market attitude variables in levels: marketing time, buy-sell recommendations, investment conditions and financial distress level. Furthermore, as we work with a panel dataset, we also perform a Levin et al. (2002) test and we do not find a common unit root in our data. Therefore, we choose a VAR over a VECM) estimation. 
Table 2 Descriptive statistics

\begin{tabular}{|c|c|c|c|c|c|c|c|c|}
\hline & Mean & Std. Dev. & Max & Min & Skewness & Kurtosis & Jarque Bera & Pro b. \\
\hline Ret & 0.01 & 0.05 & 0.20 & -0.18 & -0.21 & 5.76 & 71.71 & 0.0000 \\
\hline Retd & 0.01 & 0.07 & 0.27 & -0.25 & 0.27 & 4.92 & 36.65 & 0.0000 \\
\hline Rets & 0.01 & 0.06 & 0.25 & -0.16 & 00.18 & 5.35 & 52.03 & 0.0000 \\
\hline RPG & 0.00 & 0.07 & 0.23 & -0.21 & 0.16 & 4.73 & 28.45 & 0.0000 \\
\hline TOM & 6.76 & 1.18 & 10.50 & 4.20 & 0.54 & 3.24 & 11.38 & 0.0034 \\
\hline BUYSELL & 2.02 & 2.32 & 13.00 & 0.00 & 2.16 & 8.15 & 416.24 & 0.0000 \\
\hline INVCOND & 5.76 & 0.86 & 7.40 & 2.70 & -0.73 & 3.75 & 24.98 & 0.0000 \\
\hline DELIQ & 0.02 & 0.11 & 0.40 & -0.14 & 1.28 & 4.63 & 85.16 & 0.0000 \\
\hline DELIQ_RE & 0.03 & 0.11 & 0.33 & -0.14 & 0.92 & 3.21 & 31.28 & 0.0000 \\
\hline GDPR & 0.01 & 0.01 & 0.02 & -0.02 & -1.30 & 6.41 & 168.89 & 0.0000 \\
\hline CPI & 0.01 & 0.01 & 0.02 & -0.02 & -2.48 & 13.38 & 1219.44 & 0.0000 \\
\hline INT)\#M & 0.03 & 0.02 & 0.06 & 0.00 & -0.15 & 1.51 & 21.33 & 0.0000 \\
\hline INT10Y & 0.05 & 0.01 & 0.07 & 0.03 & 0.17 & 2.39 & 4.47 & 0.1068 \\
\hline \multicolumn{9}{|l|}{ Dummies } \\
\hline UP_ALL & 0.25 & 0.43 & 1 & 0 & 1.18 & 2.40 & 14.14 & 0.0009 \\
\hline UP_IND & 0.18 & 0.38 & 1 & 0 & 1.17 & 3.91 & 29.65 & 0.0000 \\
\hline UP_OFF & 0.28 & 0.45 & 1 & 0 & 0.98 & 1.95 & 11.66 & 0.0029 \\
\hline UP_RET & 0.21 & 0.41 & 1 & 0 & 1.42 & 3.02 & 19.16 & 0.0001 \\
\hline DOWN_ALL & 0.23 & 0.42 & 1 & 0 & 1.30 & 2.68 & 16.20 & 0.0003 \\
\hline DOWN_IND & 0.18 & 0.38 & 1 & 0 & 1.71 & 3.91 & 29.65 & 0.0000 \\
\hline DOWN_OFF & 0.19 & 0.40 & 1 & 0 & 1.56 & 3.42 & 23.42 & 0.0000 \\
\hline DOWN_RET & 0.28 & 0.45 & 1 & 0 & 0.98 & 1.95 & 11.66 & 0.0029 \\
\hline
\end{tabular}

Sector-specific indexes are used to estimate panel models. Returns, RPG, market attitude measures and dummies are all sector-specific

Table 2 presents summary statistics of all variables. By construction, we compute the RPG measure with a difference-in-difference design, which refers to a change in the reservation price gap. Therefore, we find that RPG has both positive and negative changes that cancel out each other (i.e. a mean value of zero) for the overall property sector during 1995Q1-2010Q4. Furthermore, the marketing time is on average just below 7 months. It varies between 4.2 and 10.5. The buy recommendations dominate the number of sell recommendations on average, and the investment conditions vary between 2.7 and 7.4 (on a scale of 10), with an average of 5.8. The two definitions of delinquency for commercial and overall real estate markets show similar time-series patterns. Therefore, we expect comparable results of these from the estimation models. The dummy variables indicating up and down cycles reveal that the market has experienced a down cycle for almost $23 \%$ of the time in our sample period, compared with about $25 \%$ for up cycles. The remaining $52 \%$ represents periods of relative market stability or, 'normal' conditions. With regard to the difference between property types, the retail real estate sub-sector shows the highest 
proportion of down cycle (28\%), compared with office (19\%) and industrial (18\%) sub-sectors. On the other hand, the office sub-sector has experienced the highest proportion of up cycles $(28 \%)$, compared with retail $(21 \%)$ and industrial $(18 \%)$.

Results to Test Hypothesis I: Marketing time as a signal of demand-supply mismatch Table 3 presents model estimations using marketing time as an indicator of market expectations. Columns 1 and 2 present results for respective demand- and supply-side returns, while column 3 reports results with the RPG measure. We follow the same structure for other three indicators in Tables 4, 5 and 6.

The model specifications include several macro-economic indicators such as real GDP growth rate, changes in the consumer price index, the real interest rate (10-year Treasury bond yield net of inflation), the term spread (the difference between 10-year Treasury bond yield and 3-month T-bill rate) and the marketing time variable along with its up cycle and down cycle dummy interaction terms. In Panel B, we find that the marketing time over the full cycle shows no significant feedback effect on any of the performance measures. Although sellers might offer non-price discounts, buyers may choose to wait for more availability. However, when the marketing time variable is interacted with the up and down cycle dummy variables, we find remarkable patterns emerging with a more significant results starting to appear. Specifically, during the up cycle, marketing time leads to a weakly significant (at $10 \%$ level) negative impact on the RPG measure, i.e. the price gap narrows, which is mainly caused by a positive impact on the demand-side return. It can be argued that contrary to the hypothesized case of widening RPG, if marketing time becomes longer during the up cycle, then sellers may initially resort to some non-price discounts (e.g. favorable investment and lease terms) to sell off the inventory quicker, instead of lowering the prices. However, buyers in an up cycle may still be willing to raise their reservation prices to be able to deploy their cash sooner and cease the opportunity for a superior market performance. Therefore, the buyers' distribution moves to right (refer to Fig. 1), while the sellers' distribution stays put. The net effect is a narrower price gap $(-0.0204$ over four quarters). It is important to note that we do not find any evidence of reverse causality.

On the contrary, when we look through the down cycles with a longer than usual marketing time, we find a significant negative coefficient for the supply index, suggesting that a longer marketing time during down markets may indicate slower new supply and faster inventory accumulation. In other words, sellers may have to offer lower prices, possibly also combined with non-price discounts, to offload their fast-accumulating inventory in a phase where prices are rapidly falling. It may lead them to pre-empt even further potential losses. At the same time, buyers may simply choose to stay put with no change in their reservation prices. The effect on RPG, albeit negative, is not significant as the downward adjustment in reservation prices by sellers would narrow the price gap. This argument is in line with Lizieri et al. (2012). They note that buyers dominate falling markets because sellers show more urgency to complete 
Table 3 Panel VAR Estimation - All Property and Sectors. (Reservation Price Gap and Marketing Time)

\begin{tabular}{|c|c|c|c|}
\hline & $\begin{array}{l}\text { Return Dem } \\
\text { (1) }\end{array}$ & $\begin{array}{l}\text { Return Sup } \\
\text { (2) }\end{array}$ & $\begin{array}{l}\text { RPG } \\
(3)\end{array}$ \\
\hline \multicolumn{4}{|c|}{ Panel A: Constant and autoregressive coeffiencients ( $t$-stats in italic) } \\
\hline Constant & $-0.0152 *$ & $-0.0121 *$ & $0.0203 * * *$ \\
\hline$t$-stat & -1.9177 & -1.7783 & 2.4974 \\
\hline GDPR & 0.7546 & $1.1996 * *$ & -0.1527 \\
\hline$t$-stat & 1.0900 & 2.0352 & -0.2286 \\
\hline CPI & $3.8266^{* *}$ & $3.4288 * * *$ & -1.8334 \\
\hline t-stat & 3.3338 & 3.5398 & -1.7766 \\
\hline D (INT10Y-CPI) & $2.0904 * * *$ & $2.5377 * * *$ & 0.1832 \\
\hline$t$-stat & 2.7754 & 4.0099 & 0.2691 \\
\hline D(INT_TERM) & $-3.9824 * * *$ & $-2.3786^{* * * *}$ & 1.2225 \\
\hline t-stat & -3.7613 & -2.6212 & 1.2870 \\
\hline D(CREDSPR) & $0.0354 * *$ & $0.0638 * * *$ & 0.0204 \\
\hline t-stat & 1.9726 & -2.6212 & 1.3196 \\
\hline $\mathrm{AR}(1)$ & -0.0125 & -0.1160 & -0.0872 \\
\hline t-stat & -0.1721 & -1.5902 & -1.1531 \\
\hline $\operatorname{AR}(2)$ & $-0.1622 * * *$ & -0.0250 & $-0.5482 * * *$ \\
\hline$t$-stat & -2.3232 & -0.3174 & -7.3997 \\
\hline $\mathrm{AR}(3)$ & 0.0720 & 0.0954 & -0.1135 \\
\hline t-stat & 0.9958 & 1.3171 & -1.4860 \\
\hline $\mathrm{AR}(4)$ & $0.1551 * *$ & 0.1424 & 0.0475 \\
\hline$t$-stat & 2.1063 & 1.9860 & 0.6459 \\
\hline \multicolumn{4}{|c|}{ Panel B: Sum of 4 quarterly coefficients * $p$ value of Granger-causality Wald test in italics) } \\
\hline TOM & 0.0104 & 0.0152 & -0.0042 \\
\hline$p$ value & 0.4213 & 0.7776 & 0.2806 \\
\hline TOM* UP & $0.0329 *$ & 0.0112 & $-0.0204 *$ \\
\hline$p$ value & 0.0980 & 0.8498 & 0.0866 \\
\hline TOM* DOWN & 0.0053 & $-0.0175^{*}$ & -0.0423 \\
\hline$p$ value & 0.6175 & 0.0137 & 0.1129 \\
\hline \multicolumn{4}{|c|}{ Panel C: Overall statistics } \\
\hline F-statistics & 3.17 & 2.90 & 6.11 \\
\hline Adj. R-squared & 0.18 & 0.16 & 0.34 \\
\hline Akaike AIC & -2.67 & -2.77 & -2.77 \\
\hline Schwarz SC & -2.33 & -2.61 & -2.42 \\
\hline
\end{tabular}

Results are obtained from the estimation of Eqs. $6 \mathrm{a}$ to $6 \mathrm{c}$, which report the return equations. Sector-specific price gap and marketing time (TOM) measures are used in a panel VAR with four quarterly lags. As our variable of interest is TOM, Panel B reports the Granger-causality Wald test for the 4 lags jointly. Panel C includes the main overall statistics of the models

the transactions sooner with the best possible price to exit a falling market (i.e. sellers would otherwise see part of their capital gains shrinking). Particularly, we shed light upon the fact that, under such circumstances, sellers may need to 
revise their reservation prices downwards. As previously hypothesized, we find asymmetric responses of the buyers and sellers in the up and down cycles when we use marketing time as a proxy for market expectation.

The accumulated impulse response functions (IRFs) in Fig. 5 show that the effect is weakly significant from quarter 4 in up markets (i.e. confirming the 4 joint lags significance in Table 3) and turns significant at the 95\% confidence level in quarter 4 in down markets.

Results to Test Hypothesis II: Buy-sell recommendations as a signal of demand-supply gap Next, we turn to the analysis of demand-supply mismatches by using buy-sell recommendations from the RERC survey. Table 4 presents the models using a ratio of the buy and sell recommendations as an indicator of market expectations. If the ratio is larger than 1 , then there is more buy than sell recommendations, while a ratio of less than 1 indicates prevalence of sell recommendations. We follow the same reporting structure as in Table 3 . We mainly focus on the results for the two phases (up and down) of cycles. We do not find any evidence of reverse causality.

During the up cycle, there is a significant negative impact on the RPG, which changes in sign to a significant positive effect during the down cycles. The effect sizes are -0.2606 and 0.1592 , respectively. During the up market, buyers are willing to increase their reservation prices (i.e. towards right in Fig. 1) to be able to access a wellperforming market. On the other hand, sellers may not need to change their reservation prices, as there is a larger number of willing buyers. The long-term commitments of institutional investors may be a factor in them not being able to revise their reservation prices. Due to a higher level of willingness to revise their reservation prices by buyers, the net effect on RPG is negative, i.e. the gap narrows, leading to a larger number of completions of transactions.

On the contrary, during the down cycle, buyers may lower their reservation prices faster than sellers as sellers may consider a combination of non-price and price discounts, instead of assorting to price discounts straightway. Consequently, the gap (RPG) may widen, leading to less frequency and likelihood for completions, which, in turn, could lead to a supply overhang.

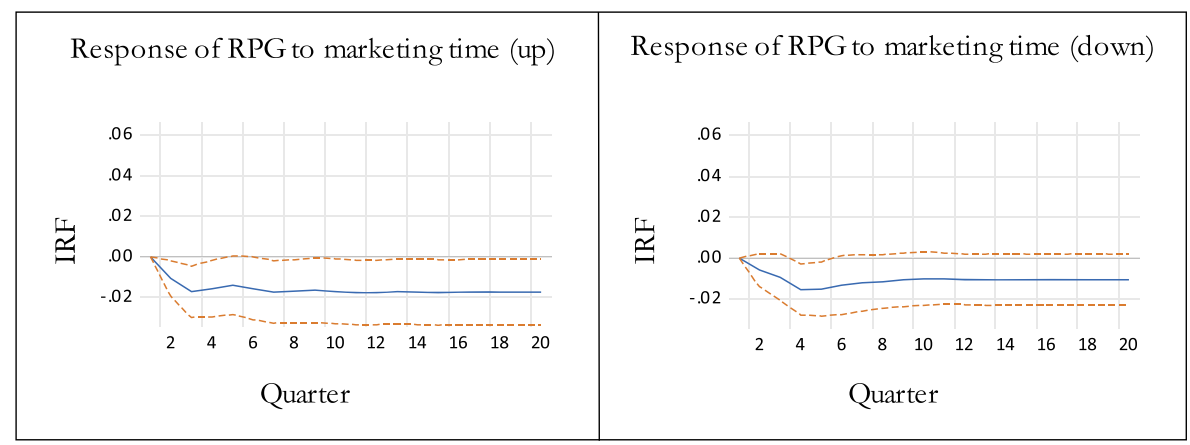

Fig. 5 Accumulated impulse response functions (IRFs) of the reservation price gap (RPG) in up and down markets. Note: The graphs contain the accumulated IRFs of the RPG to innovations of marketing time in up (left) and down (right) markets. The two dotted lines represent the 95\% confidence interval 
Table 4 Panel VAR Estimation - All Property and Sectors. (Reservation Price Gap and Buy/Sell Recommendations)

\begin{tabular}{|c|c|c|c|}
\hline & $\begin{array}{l}\text { Return DEM } \\
\text { (1) }\end{array}$ & $\begin{array}{l}\text { Return Sup } \\
\text { (2) }\end{array}$ & $\begin{array}{l}\text { RPG } \\
(3)\end{array}$ \\
\hline \multicolumn{4}{|c|}{ Panel A: Constant and autoregressive coeffiencients ( $t$-stats in italic) } \\
\hline Constant & -0.0125 & -0.0120 & 0.0124 \\
\hline$t$-stat & -1.2033 & -1.2006 & 1.1212 \\
\hline GDPR & 0.4330 & $1.3652^{* *}$ & -0.0020 \\
\hline$t$-stat & 0.5734 & 1.9805 & -0.0026 \\
\hline CPI & $3.8973^{* * *}$ & $3.0622 * * *$ & -1.1552 \\
\hline t-stat & 2.5849 & 2.2689 & -0.7829 \\
\hline D(INT10Y-CPI) & $1.4531^{*}$ & $2.1203 * * *$ & 0.9413 \\
\hline$t$-stat & 1.7586 & 2.8582 & 1.1666 \\
\hline D(INT_TERM) & $-3.8064 * * *$ & $-2.0454 * * *$ & 1.0237 \\
\hline$t$-stat & -3.9276 & -2.3842 & 1.0929 \\
\hline D(CREDSPR) & $0.0345^{* *}$ & $0.0432 * * *$ & 0.0113 \\
\hline t-stat & 1.9789 & 2.7419 & 0.6787 \\
\hline $\mathrm{AR}(1)$ & 0.0067 & -0.0520 & 0.0235 \\
\hline$t$-stat & 0.0963 & -0.7684 & 0.3493 \\
\hline $\mathrm{AR}(2)$ & $-0.1727 * * *$ & -0.0379 & $-0.446^{* * *}$ \\
\hline t-stat & -2.6990 & -0.5383 & -7.0347 \\
\hline $\mathrm{AR}(3)$ & 0.1054 & 0.0921 & 0.0005 \\
\hline$t$-stat & 1.6405 & 1.2982 & 0.0071 \\
\hline $\operatorname{AR}(4)$ & $0.117 *$ & $0.1261 *$ & $0.1508 * * *$ \\
\hline$t$-stat & 1.7821 & 1.7978 & 2.2940 \\
\hline \multicolumn{4}{|c|}{ Panel B: Sum of 4 quarterly coeffiecients ( $p$ value of Granger-causality Wald test in italics) } \\
\hline BUYSELL & 0.1042 & 0.0519 & -0.0767 \\
\hline$p$ value & 0.2991 & 0.6782 & 0.1208 \\
\hline BUYSELL * UP & 0.2635 & -0.1154 & -0.2606 \\
\hline$p$ value & 0.1970 & 0.3183 & 0.0353 \\
\hline BUYSELL * DOWN & -0.0305 & -0.0008 & $0.1592 *$ \\
\hline$p$ value & 0.0349 & 0.6816 & 0.0961 \\
\hline \multicolumn{4}{|c|}{ Panel C: Overall statisticsReturn } \\
\hline F-statistic & 4.53 & 2.35 & 7.27 \\
\hline Adj. R-squared & 0.24 & 0.11 & 0.36 \\
\hline Akaike AIC & -2.76 & -2.95 & -2.76 \\
\hline Schwarz SC & -2.44 & -2.63 & -2.44 \\
\hline
\end{tabular}

Results are obtained from the estimation of Eqs. 7a to 7c. Sector-specific price gap and buy vs sell recommendations (BUYSELL) measures are used in a panel VAR with four quarterly lags. As our variable of interest is BUYSELL, Panel B reports the Granger-causality Wald test for the 4 lags jointly. Panel C includes the main overall statistics of the models 
Figure 6 shows the accumulated IRFs in up (left) and down markets, where buy/sell recommendations respectively show their impact from quarter 4 to 8 in rising markets and those tend to be weakly significant around the same period when markets fall.

Results to Test Hypothesis III: Investment conditions as a market indicator Investment conditions, as revealed by the RERC survey respondents, can serve as an important indicator of market expectations. We find a significant difference in the feedback effects of investment conditions during up and down cycles. While the effect of an improvement in investment conditions is positive in both cycles, it is not substantial and significant in the up cycles. However, it is significant in the down cycles. It is plausible that investment conditions can improve in a downturn due to interventions by the Central Banks and other Government agencies for example, monetary policy interventions such as rate cuts, quantitative easing and also, fiscal policy measures that can elevate market expectation and open up new channels of investments in the economy. As investment conditions improve, liquidity in the market improves and, therefore, we may expect to find a larger volume of transactions. Increasing transaction volumes may encourage sellers to act as price-setters as they see a higher than the average number of prospective buyers per sale item or property. When the investment conditions worsen after a period of significant growth, buyers may consider this signal more readily than sellers and attempt to take advantage of the situation. Buyers would exercise cautious optimism, bargain harder, and they may only want to participate if they are guaranteed a price drop, especially after a long period of growth. Moreover, we do not find any evidence of reverse causality.

On the other hand, sellers may exercise more patience and be willing to wait longer before starting to revise their reservation prices downwards. Even if sellers stand to lose further by not exiting the market soon enough, they may still be prepared to face a higher risk of price-cuts. It may be due to the fact that they have either accumulated significant capital gains in the preceding growth period or, they cannot realize the financial losses on their books for the current period or, both. Our results for the down cycles confirm such

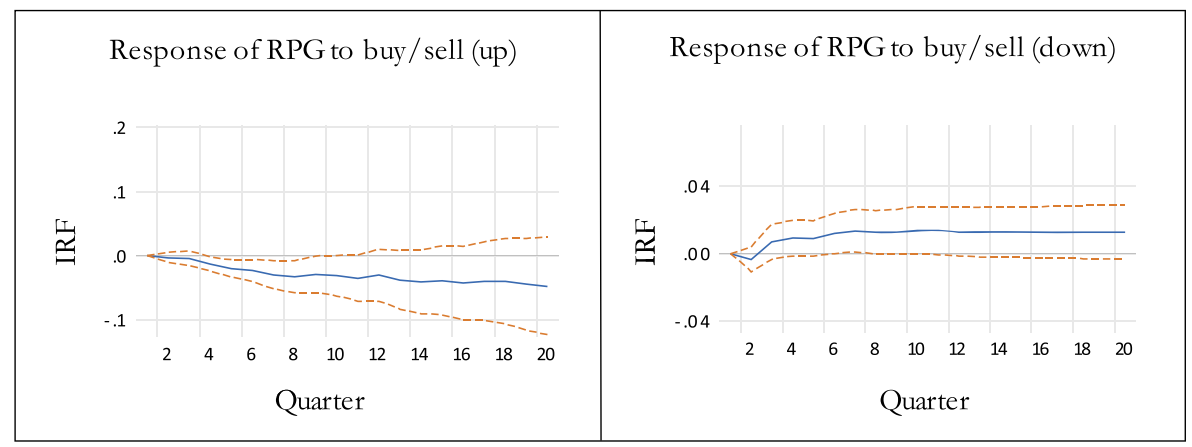

Fig. 6 Accumulated impulse response functions (IRFs) of the reservation price gap (RPG) in up and down markets. Note: The graphs contain the accumulated IRFs of the RPG to innovations of buy/sell recommendations in up (left) and down (right) markets. The two dotted lines represent the $95 \%$ confidence interval 
Table 5 Panel VAR Estimation - All Property and Sectors. (Reservation Price Gap and Investment Conditions)

\begin{tabular}{|c|c|c|c|}
\hline & $\begin{array}{l}\text { Return Dem } \\
\text { (1) }\end{array}$ & $\begin{array}{l}\text { Return Sup } \\
\text { (2) }\end{array}$ & $\begin{array}{l}\text { RPG } \\
\text { (3) }\end{array}$ \\
\hline \multicolumn{4}{|c|}{ Panel A: Constant and autoregressive coeffiencients ( $t$-stats in italics) } \\
\hline Constant & -0.0153 & -0.0034 & $0.0224 * * *$ \\
\hline t-stat & -1.6200 & -0.3893 & 2.2951 \\
\hline GDPR & 0.4248 & $1.0925^{*}$ & -0.3764 \\
\hline t-stat & 0.6204 & 1.8400 & -0.5310 \\
\hline CPI & $3.3777 * * *$ & $2.1376^{* * * *}$ & -1.5805 \\
\hline t-stat & 2.9283 & 2.1265 & -1.3742 \\
\hline D(INT10Y-CPI) & $2.0294 * * *$ & $1.8846^{* * * *}$ & -0.0817 \\
\hline t-stat & 2.8696 & 3.0872 & -0.1146 \\
\hline D(INT_TERM) & $-5.1128^{* * * *}$ & $-2.3518^{* * *} *$ & $2.7434 * * *$ \\
\hline t-stat & -4.9755 & -2.6803 & 2.7034 \\
\hline D(CREDSPR) & 0.0226 & $0.0452 * * *$ & 0.0176 \\
\hline t-stat & 1.2898 & 3.0029 & 1.0063 \\
\hline $\operatorname{AR}(1)$ & 0.0130 & -0.0668 & -0.0170 \\
\hline t-stat & 0.1999 & -0.9377 & -0.2535 \\
\hline $\operatorname{AR}(2)$ & $-0.171 * * *$ & -0.0509 & $-0.5399 * * *$ \\
\hline t-stat & -2.6933 & -0.6974 & -8.1622 \\
\hline $\operatorname{AR}(3)$ & 0.1028 & 0.0474 & -0.0431 \\
\hline t-stat & 1.5913 & 0.6346 & -0.6296 \\
\hline $\mathrm{AR}(4)$ & $0.1139 *$ & $0.134 *$ & 0.0244 \\
\hline$t$-stat & 1.6922 & 1.7725 & 0.3541 \\
\hline \multicolumn{4}{|c|}{ Panel B: Sum of 4 quarterly coeffiecients ( $p$ value of Granger-causality Wald test in italics) } \\
\hline INVCOND & 0.0334 & -0.0020 & $-0.0454^{*}$ \\
\hline$p$ value & 0.1766 & 0.7060 & 0.0645 \\
\hline INVCOND * UP & -0.0197 & -0.0148 & 0.0341 \\
\hline$p$ value & 0.7123 & 0.6513 & 0.2084 \\
\hline INVCOND $*$ DOWN & $-0.0503 *$ & 0.0234 & $0.1006^{* * *}$ \\
\hline$p$ value & 0.0953 & 0.9197 & 0.0009 \\
\hline \multicolumn{4}{|c|}{ Panel C: Overall statisticsReturn } \\
\hline F-statistic & 3.58 & 2.28 & 6.20 \\
\hline Adj. R-squared & 0.18 & 0.10 & 0.30 \\
\hline Akaike AIC & -2.73 & -2.99 & -2.72 \\
\hline Schwarz SCPanel & -2.43 & -2.68 & -2.42 \\
\hline
\end{tabular}

Results are obtained from the estimation of Eqs. $8 \mathrm{a}$ to $8 \mathrm{c}$. Sector-specific price gap and investment conditions (INVCOND) measures are used in a panel VAR with four quarterly lags. As our variable of interest is INVCOND, Panel B reports the Granger-causality Wald test for the 4 lags jointly. Panel $\mathrm{C}$ includes the main overall statistics of the models 
behavior with the sellers' return not being significant and, the buyers' return is negative with an overall widening of RPG, as the buyers' distribution move to the left.

In Fig. 7 accumulated IRFs show no significance in up markets, while some significance is found in down markets around quarter 4, but it subsequently fades away.

Results to test Hypothesis IV: Presence of 'vulture' investors during down cycles The distressed market conditions provide a unique opportunity for investors to accumulate assets and build portfolios at relatively very low prices. Particularly, there is ample evidence of 'vulture' investing in real estate markets, especially in post-GFC periods. 'Vulture' investors follow a very different strategy than typical investors do and thus, they may defy standard market predictions. Their strategy of 'picking from the ruins' is quite contrary to other typical investors' strategies, and this may further exacerbate the market frictions. We test such possibility in Table 6 , where we use a delinquency measure as a proxy for the prevalence of distressed asset sales.

Since delinquency is particularly prevalent in down cycles, the results for up cycles are not significant and those are not quite relevant either. This is expected due to presence of 'vulture' investors, and distress sales only become significant during deep recessionary periods. During such times, buyers act as price-setters and sellers must accept a lot lower bargaining power, especially if they hold distressed assets. We find that delinquency affects sellers directly, thus forcing them to lower their reservation prices much faster than the buyers, to be able to meet debt obligations. Buyers also revise their reservation prices downward during down cycles, but the rate at which they revise it is much slower than that of sellers'. As a result, with much faster downward revision in seller's return - i.e. leftward movement in sellers' distribution in Fig. 1 - the $R P G$ measure may narrow significantly during down cycles, leading to statistically significant compression of -0.2434 in RPG. The coefficient is negative for both sellers and buyers. As the distress level deepens (i.e. the volume of

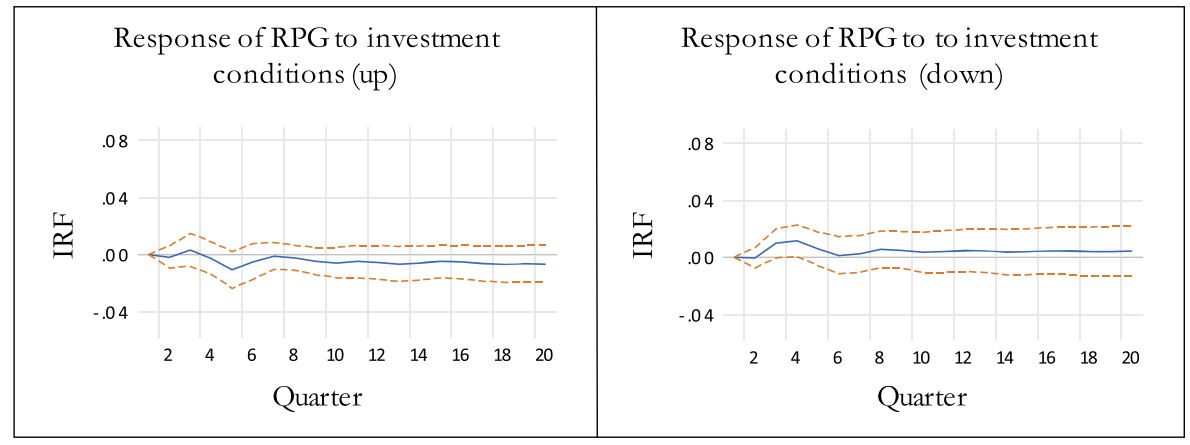

Fig. 7 Accumulated impulse response functions (IRFs) of the reservation price gap (RPG) in up and down markets. Note: The graphs contain the accumulated IRFs of the RPG to innovations of investment conditions in up (left) and down (right) markets. The two dotted lines represent the $95 \%$ confidence interval 
Table 6 Panel VAR Estimation - All Property and Sectors. (Reservation Price Gap and Financial Distress)

\begin{tabular}{lll}
\hline Return Dem & Return Sup & RPG \\
$(1)$ & $(2)$ & $(3)$
\end{tabular}

Panel A: Constant and autoregressive coeffiencients ( $t$-stats in italics)

\begin{tabular}{|c|c|c|c|}
\hline Constant & -0.0152 & 0.0013 & $0.0232 * * *$ \\
\hline t-stat & -1.6064 & 0.1548 & 2.5085 \\
\hline GDPR & 1.0678 & 0.1891 & -1.1917 \\
\hline t-stat & 1.3490 & 0.2704 & -1.5254 \\
\hline CPI & $4.107 * * *$ & $2.5445 * * *$ & $-2.8673 * * *$ \\
\hline t-stat & 3.3618 & 2.3853 & -2.4408 \\
\hline D(INT10Y-CPI) & 0.7996 & $3.5075 * * *$ & $1.7998 * *$ \\
\hline t-stat & 0.8902 & 4.4932 & 2.1082 \\
\hline D(INT_TERM) & -1.5729 & $-2.6718 * * *$ & -1.2061 \\
\hline t-stat & -1.5578 & -3.0420 & -1.2061 \\
\hline D(CREDSPR) & 0.0124 & $0.0694 * * *$ & $0.0423 * * *$ \\
\hline t-stat & 0.5950 & 3.7718 & 2.2058 \\
\hline $\mathrm{AR}(1)$ & -0.0115 & -0.0856 & -0.0480 \\
\hline t-stat & -0.1738 & -1.3134 & -0.7613 \\
\hline $\mathrm{AR}(2)$ & $-0.1331 * *$ & -0.0647 & $-0.4254 * * *$ \\
\hline t-stat & -2.1169 & -0.9751 & -6.9614 \\
\hline $\mathrm{AR}(3)$ & $0.1148^{*}$ & 0.0146 & -0.0070 \\
\hline t-stat & 1.8380 & 0.2307 & -0.1167 \\
\hline $\mathrm{AR}(4)$ & $0.1289 * *$ & 0.0622 & $0.1013 *$ \\
\hline t-stat & $0.1289 * *$ & 0.9829 & 1.7024 \\
\hline
\end{tabular}

Panel B: Sum of 4 quarterly coeffiecients ( $p$ value of Granger-causality Wald test in italics)

$\begin{array}{lccc}\text { DELIQ } & 0.0119 & -0.0057 & 0.0038 \\ p \text { value } & 0.3736 & 0.3476 & 0.1606 \\ \text { DELIQ * UP } & -0.1738 & 0.0912 & 0.2654 \\ p \text { value } & 0.4048 & 0.2554 & 0.4425 \\ \text { DELIQ * DOWN } & -0.3702 * & -0.7247 * * * & -0.2434 * * * \\ p \text { value } & 0.0692 & 0.0000 & 0.0000\end{array}$

Panel C: Overall statisticsReturn

$\begin{array}{llll}\text { F-statistic } & 4.98 & 3.43 & 8.75 \\ \text { Adj. R-squared } & 0.25 & 0.17 & 0.39 \\ \text { Akaike AIC } & -2.83 & -3.07 & -2.86 \\ \text { Schwarz SC } & -2.52 & -2.76 & -2.55\end{array}$

Results are obtained from the estimation of Eqs. 9a to 9c. Sector-specific price gap and delinquency rate (DELIQ) measures are used in a panel VAR with four quarterly lags. As our variable of interest is DELIQ, Panel B reports the Granger-causality Wald test for the 4 lags jointly. Panel $\mathrm{C}$ includes the main overall statistics of the models 
distress properties for sale goes up), the downward revision in the reservation prices becomes faster. However, such reductions are much sharper for sellers than for buyers. Moreover, a narrowing price gap may bring some liquidity if sellers need to reduce their inventories.

Figure 8 reports the accumulated IRFs, which confirm our aforementioned results showing strong significance of delinquency rates as opportunities for vulture investors materialize in down markets where the gap is significantly reduced from quarter 4 for a relatively long period (almost 3 years).

Overall, the results from all four tables reflect clear evidence of bargaining in the market. Such bargaining activities behave differently in recessionary periods compared to from other times in the economic cycle. Our empirical results indicate strong evidence of price adjustments and more importantly, they reflect asymmetry in price movements during various phases of economic cycles. These results are consistent with our theoretical hypotheses described in "Theoretical Underpinning and Testable Hypotheses" section. Our analysis suggests that buyers' or sellers' attitude and resultant revisions in their reservation prices lead to strong and statistically significant feedback effects in price determination. The results are robust when we pool information from all three sub-sectors (which are available upon request). Our results support the possibility of asymmetric responses during the boom, normal and recessionary periods.

\section{Feedback Loops and the Impact of Pricing on Investors' Attitudes}

As a further step in our analysis, we present the impulse response functions of investors' attitudes to price changes. In fact, there may be a feedback loop where investors read into the pricing mechanism and adjust their expectations. Figure 9 presents IRFs derived from the second equation of our VAR models assessing $R P G$ for four different proxies of investors' attitudes. We find that the strongest feedback loop is found for both buy/sell recommendations (Panel

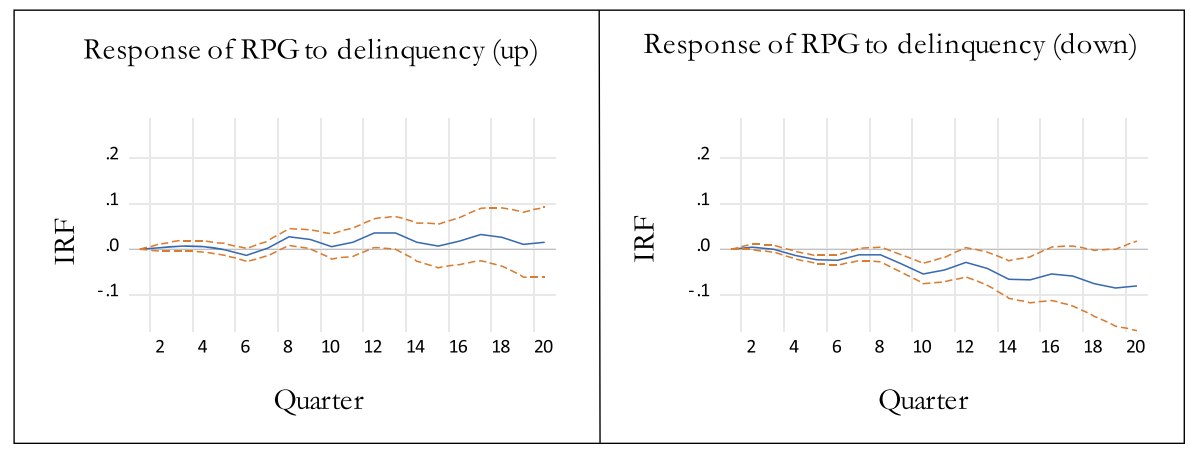

Fig. 8 Accumulated impulse response functions (IRFs) of the reservation price gap (RPG) in up and down markets. Note: The graphs contain the accumulated IRFs of the RPG to innovations of delinquency rates in up (left) and down (right) markets. The two dotted lines represent the 95\% confidence interval 
B) and investment conditions (Panel C), which tend to deteriorate as investors observe a widening gap between reservation prices of buyers and sellers. The innovation tends to be embedded in investors' attitudes two quarters after the new information in the $R P G$ measure is released and the effect fades away after about 8 to 10 quarters. A similar impact of pricing on delinquency rates (and attitudes of vulture investors) is shown in Panel D, where delinquency rate increases with the widening RPG. This is particularly the case over first six quarters as the new information in RPG becomes available.

\section{Robustness Checks: Fixed Effects and Lags}

We estimate Eqs. 6 to 9 (a to c) with four lags including sector fixed effects, and we find a confirmation of our main findings. Table 7 shows the results obtained using the reservation price gap $\left(R P G_{i t}\right)$ as presented in Eqs. 6a to 9a. Four columns report estimates from Eq. 7 (including the sector fixed effects) using four different proxies for market expectations $\left(A t t_{i, t-j}\right)$ - buy-sell recommendations $\left(B U Y S E L L_{i t}\right)$ in column 1, marketing time $\left(T O M_{i t}\right)$ in column 2, investment conditions (INVCOND ${ }_{\text {it }}$ ) in column 3 and delinquency rates of commercial real estate (DELIQ_CRE $\mathrm{it}_{\mathrm{it}}$ ) in column 4. Clearly, both the coefficients and their significance are similar to the ones obtained for models without fixed effects (refer to 3rd column of Tables 3, 4, 5 and 6). Estimations using the demand- and supply-side returns (respectively $\operatorname{Retd}_{i, t-j}$ in Eqs. $6 \mathrm{~b}$ to $9 \mathrm{~b}$ and

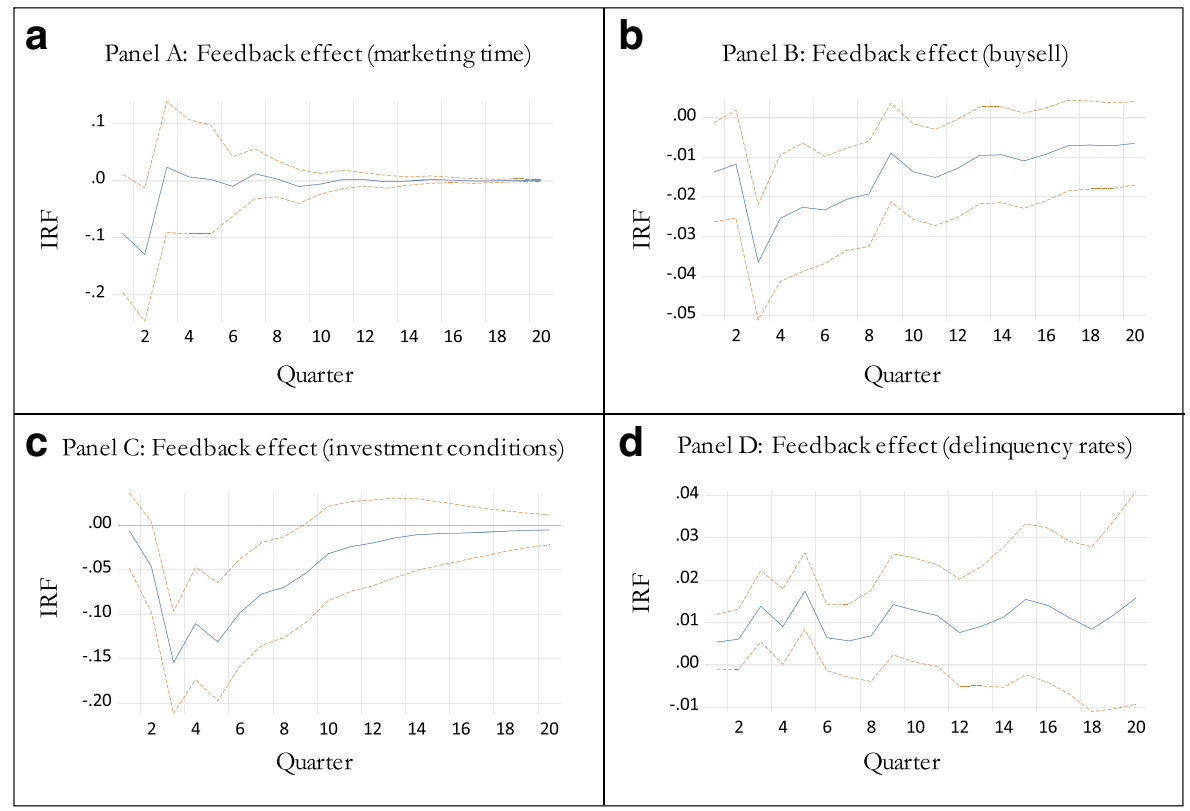

Fig. 9 Feedback loop - impulse response functions (IRFs) of investor's attitudes. Note: The graphs contain the IRFs of investor's attitudes (marketing time, buy/sell recommendations, investment conditions and delinquency rates) to innovation in the reservation price gap (RPG). The two dotted lines represent the $95 \%$ confidence interval 
Rets $_{i, t-j}$ in Eqs. 6c to 9c) also show results in line with our main findings. However, we do not present those for the sake of parsimony in reporting.

Finally, we estimate Eqs. 6 to 9 (a through c), incorporating sector fixed effects and using 8 lags. We report our results in Table 8 (similar structure of four columns as in Table 7). Overall, our main findings are confirmed, and we generally obtain coefficients with a similar sign and significance. The impulse response functions also reveal similar results, and we do not report those for the sake of parsimonious reporting.

\section{Conclusion}

We examine various indicators of demand-supply imbalances and their relationship to the dynamics of price determination in real estate market. Our theoretical hypotheses are based on the possibility of shifts in bargaining power and heterogeneous signal processing by buyers and sellers that can lead to a diverse range of actions for buy/sell decisions and asymmetric adjustments in reservation prices. Several real estate sectors over 1995-2010 are studied to inform our analysis. The timeframe of our analysis allows us to observe market dynamics over two economic cycles. Our empirical framework uses a range of indicators of investment attitudes and market expectations (marketing time, buy-sell recommendation, investment conditions and financial distress measures) to explain asymmetry in reservation price adjustments within a panel VAR approach.

The main results suggest strong and statistically significant feedback effects from these indicators in price determination. We find evidence of asymmetric responses during the boom, normal and recessionary periods. The demandsupply mismatch and indicators of market expectations appear to exert much more pronounced effects during down cycles than up cycles. This is probably due to a high level of cautiousness being exercised more often by both buyers and sellers during the down cycles, and any revisions to price expectations and reservation prices are much more carefully thought through and executed by the economic agents.

These results have important implications for the investment market and forecasting exercises. The underlying theme of this paper revolves around shifts in bargaining power from buyers to sellers and vice versa depending on the market conditions. The main findings of this paper can inform institutional interventions for the property and broader financial sectors during the times of market turmoil. An effective management of market expectations is key to achieve market stability and minimize the aftershocks. Future research may investigate cross-sectional and multi-country evidence of the findings in this paper, as the size and direction of the effects may depend on the countryspecific institutional frameworks and regulatory constraints affecting investment conditions for real estate. 
Table 7 Panel VAR Estimation - All Property and Sectors. (Reservation Price Gap and Investors' Attitudes). With Sector Fixed Effects and 4 Lags

\begin{tabular}{|c|c|c|c|c|}
\hline & $\begin{array}{l}\text { Marketing Time } \\
\text { (1) }\end{array}$ & $\begin{array}{l}\text { Buy Sell } \\
(2)\end{array}$ & $\begin{array}{l}\text { Investment Condition } \\
\text { (3) }\end{array}$ & $\begin{array}{l}\text { Delinquency } \\
\text { (4) }\end{array}$ \\
\hline \multicolumn{5}{|c|}{ Panel A: Constant and autoregressive coeffiencients ( $t$-stats in italics) } \\
\hline Constant & 0.0251 & 0.0131 & 0.0251 & 0.0259 \\
\hline$t$-stat & 0.0348 & 0.0475 & 0.0432 & 0.0674 \\
\hline GDPR & -0.1654 & -0.0088 & -0.3836 & -1.1954 \\
\hline$t$-stat & -0.2461 & -0.0112 & -0.05383 & -1.5221 \\
\hline CPI & $-1.8625^{*}$ & -1.1634 & -1.5833 & $-2.8694 * * *$ \\
\hline t-stat & -1.7932 & -0.7831 & -1.3693 & -2.4298 \\
\hline D(INT10Y-CPI) & 0.1545 & 0.9367 & -0.0855 & $1.7969 * *$ \\
\hline$t$-stat & 0.2253 & 1.1530 & -0.1192 & 2.0937 \\
\hline D(INT_TERM) & 1.2516 & 1.0303 & $2.752 * * *$ & -1.2019 \\
\hline t-stat & 1.3079 & 1.0924 & 2.6974 & -1.2750 \\
\hline D(CREDSPR) & 0.0202 & 0.0113 & 0.0175 & $0.0422 * * *$ \\
\hline$t$-stat & 1.2964 & 0.6712 & 0.9965 & 2.1933 \\
\hline $\operatorname{AR}(1)$ & -0.0926 & 0.0222 & -0.0186 & -0.0495 \\
\hline$t$-stat & -1.2125 & 0.3264 & -0.2763 & -0.7806 \\
\hline $\mathrm{AR}(2)$ & $-0.552 * * *$ & $-0.447 * * *$ & $-0.5413 * * *$ & $-0.4266^{* * * *}$ \\
\hline$t$-stat & -7.3920 & -6.9977 & -8.1361 & -6.9407 \\
\hline $\operatorname{AR}(3)$ & -0.1194 & -0.0010 & -0.0444 & -0.0081 \\
\hline$t$-stat & -1.5473 & -0.0146 & -0.6452 & -0.1337 \\
\hline $\mathrm{AR}(4)$ & 0.0430 & $0.1493 * * *$ & 0.0227 & 0.1000 \\
\hline$t$-stat & 0.5802 & 2.2516 & 0.3280 & 1.6712 \\
\hline \multicolumn{5}{|c|}{ Panel B: Sum of 4 quarterly coeffiecients ( $p$ value of Granger-causality Wald test in italics) } \\
\hline $\mathrm{Att}_{\mathrm{it}}$ & -0.0045 & -0.0774 & $-0.0456^{*}$ & 0.0038 \\
\hline$p$ value & 0.2938 & 0.1253 & 0.0660 & 0.1652 \\
\hline $\mathrm{Att}_{\mathrm{it}} * \mathrm{UP}$ Dummy & -0.0175 & $-0.2599 * *$ & 0.0343 & 0.2656 \\
\hline$p$ value & 0.1011 & 0.0372 & 0.2099 & 0.4484 \\
\hline $\mathrm{Att}_{\mathrm{it}} *$ DOWN Dummy & -0.0440 & $0.1606^{*}$ & $0.1009 * * *$ & $-0.2422 * * *$ \\
\hline$p$ value & 0.1038 & 0.0993 & 0.0009 & 0.0000 \\
\hline \multicolumn{5}{|l|}{ Panel C: Overall statistics } \\
\hline F-statistic & 5.32 & 6.29 & 5.39 & 7.60 \\
\hline Adj. R-squared & 0.33 & 0.35 & 0.30 & 0.39 \\
\hline Akaike AIC & -2.74 & -2.74 & -2.70 & -2.84 \\
\hline Schwarz SC & -2.35 & -2.37 & -2.35 & -2.49 \\
\hline
\end{tabular}

Results for reservation price gap (RPG) measures are obtained from the estimation of Eq. 5a in a panel VAR with four quarterly lags and sector fixed effects. Each column reports the results using a different Investors Attitude (Att ${ }_{i}$ ) measure: marketing time (1), buy vs sell recommendations (2), investment conditions (3) and delinquency rates (3), in a panel VAR with four quarterly lags. Panel B reports the Granger-causality Wald test for the 4 lags of the investors' attitude jointly. Panel $\mathrm{C}$ includes the main overall statistics of the models 
Table 8 Panel VAR Estimation - All Property and Sectors. (Reservation Price Gap and Investors' Attitudes). With Sector Fixed Effects and 8 Lags

\begin{tabular}{|c|c|c|c|c|}
\hline & $\begin{array}{l}\text { Marketing Time } \\
\text { (1) }\end{array}$ & $\begin{array}{l}\text { Buy Sell } \\
\text { (2) }\end{array}$ & $\begin{array}{l}\text { Investment Condition } \\
\text { (3) }\end{array}$ & $\begin{array}{l}\text { Delinquency } \\
\text { (4) }\end{array}$ \\
\hline \multicolumn{5}{|c|}{ Panel A: Constant and autoregressive coeffiencients ( $t$-stats in italics) } \\
\hline Constant & 0.0279 & 0.0411 & 0.227 & 0.0105 \\
\hline$t$-stat & 0.0289 & 0.0626 & 0.0241 & 0.0073 \\
\hline GDPR & -0.7100 & $2.3086^{* * * *}$ & -0.8578 & 0.1268 \\
\hline$t$-stat & -0.8354 & 2.2718 & -0.9004 & 0.1312 \\
\hline CPI & -1.6295 & $-4.3397 * * *$ & -2.1220 & -0.7263 \\
\hline$t$-stat & -1.3003 & -2.3117 & -1.3682 & -0.5108 \\
\hline D(INT10Y-CPI) & 0.3384 & -1.5296 & -0.5940 & $4.1741 * * *$ \\
\hline$t$-stat & 0.4405 & -1.3262 & -0.6561 & 4.1932 \\
\hline D(INT_TERM) & 0.3502 & $2.2522 * *$ & $2.6305^{* *}$ & $-3.4287 * * *$ \\
\hline t-stat & 0.2997 & 2.1055 & 1.9617 & -2.9002 \\
\hline D(CREDSPR) & 0.0144 & $-0.0643 * *$ & -0.0152 & $0.1143 * * *$ \\
\hline$t$-stat & 0.7269 & -2.2081 & -0.6770 & 3.1918 \\
\hline $\operatorname{AR}(1)$ & -0.0893 & -0.0571 & -0.0597 & $-0.1828 * * *$ \\
\hline t-stat & -1.0292 & -0.7870 & -0.7706 & -2.6587 \\
\hline $\mathrm{AR}(2)$ & $-0.5765 * * *$ & $-0.5414 * * *$ & $-05545^{* * *}$ & $-0.6144 * *$ \\
\hline t-stat & -7.0053 & -7.7342 & -7.7452 & -8.6277 \\
\hline $\mathrm{AR}(3)$ & -0.1299 & 0.0449 & -0.1111 & $-0.1675^{* *}$ \\
\hline$t$-stat & -1.3082 & 0.5477 & -1.2251 & -2.0342 \\
\hline $\mathrm{AR}(4)$ & -0.0449 & -0.0008 & -0.0706 & -0.1158 \\
\hline$t$-stat & -0.4727 & -0.0098 & -0.7965 & -1.3905 \\
\hline \multicolumn{5}{|c|}{ Panel B: Sum of 4 quarterly coeffiecients ( $p$ value of Granger-causality Wald test in italics) } \\
\hline $\mathrm{Att}_{\mathrm{it}}$ & $-0.0188 * *$ & $-0.2432 * * *$ & $-0.0539 *$ & $1.6456 * * *$ \\
\hline$p$ value & 0.0170 & 0.0065 & 0.0892 & 0.0000 \\
\hline $\mathrm{Att}_{\mathrm{it}} * \mathrm{UP}$ Dummy & $-0.033^{* *}$ & $-1.4078 * * *$ & $0.1796^{* *}$ & $-0.706^{* * *}$ \\
\hline$p$ value & 0.0433 & 0.0056 & 0.0100 & 0.0017 \\
\hline Att $_{i t} *$ DOWN Dummy & -0.0654 & $1.2921 * * *$ & $0.1085^{* *}$ & $-2.2919 * * *$ \\
\hline$p$ value & 0.2444 & 0.0000 & 0.0135 & 0.0000 \\
\hline \multicolumn{5}{|l|}{ Panel C: Overall statistics } \\
\hline F-statistic & 3.57 & 5.74 & 4.56 & 7.00 \\
\hline Adj. R-squared & 0.35 & 0.46 & 0.38 & 0.51 \\
\hline Akaike AIC & -2.69 & -2.89 & -2.72 & -2.95 \\
\hline Schwarz SC & -2.01 & -2.26 & -2.12 & -2.35 \\
\hline
\end{tabular}

Results for reservation price gap (RPG) measures are obtained from the estimation of Eq. 5a in a panel VAR with eight quarterly lags and sector fixed effects. Each column reports the results using a different investors' attitude $\left(A t t_{i t}\right)$ measure: marketing time (1), buy vs sell recommendations (2), investment conditions (3) and delinquency rates (3), in a panel VAR with four quarterly lags. Panel B reports the Granger-causality Wald test for the 4 lags of the investors' attitude jointly. Panel $\mathrm{C}$ includes the main overall statistics of the models 
Acknowledgements We would like to thank participants at the WEZ Research Symposium. All remaining errors are ours.

Open Access This article is licensed under a Creative Commons Attribution 4.0 International License, which permits use, sharing, adaptation, distribution and reproduction in any medium or format, as long as you give appropriate credit to the original author(s) and the source, provide a link to the Creative Commons licence, and indicate if changes were made. The images or other third party material in this article are included in the article's Creative Commons licence, unless indicated otherwise in a credit line to the material. If material is not included in the article's Creative Commons licence and your intended use is not permitted by statutory regulation or exceeds the permitted use, you will need to obtain permission directly from the copyright holder. To view a copy of this licence, visit http://creativecommons.org/licenses/by/4.0/.

\section{References}

Benefield, J. D., \& Hardin, W. G. (2015). Does time-on-market measurement matter? The Journal of Real Estate Finance and Economics, 50(1), 52-73.

Benefield, J., Cain, C., \& Johnson, K. (2014). A review of literature utilizing simultaneous modeling techniques for property price and time-on-market. The Journal of Real Estate Literature, 22(2), 149-175.

Bond, S., Crosby, N., Hwang, S., Key, T., Lizieri, C., Matysiak, G., McAllister, P. \& Ward, C. (2004). Liquidity in commercial property markets. Investment Property Forum. Available at https://www.ipf.org. uk/resourceLibrary/liquidity-in-commercial-property-markets-april-2004-.html.

Chiu, J., Chung, H., \& Ho, K. Y. (2014). Fear sentiment, liquidity, and trading behavior: Evidence from the index ETF market. Review of Pacific Basin Financial Markets and Policies, 17(03), 1450017.

Choi, H., \& Varian, H. (2012). Predicting the present with Google trends. The Economic Record, 88, 2-9.

Clayton, J., Ling, D. C., \& Naranjo, A. (2009). Commercial real estate valuation: Fundamentals versus investor sentiment. The Journal of Real Estate Finance and Economics, 38(1), 5-37.

Das, P. K., Freybote, J., \& Marcato, G. (2015). An investigation into sentiment-induced institutional trading behavior and asset pricing in the REIT market. The Journal of Real Estate Finance and Economics, 51(2), 160-189.

Fisher, J., Gatzlaff, D., Geltner, D., \& Haurin, D. (2003). Controlling for the impact of variable liquidity in commercial real estate price indices. Real Estate Economics, 31(2), 269-303.

Fisher, J., Geltner, D., \& Pollakowski, H. (2007). A quarterly transactions-based index of institutional real estate investment performance and movements in supply and demand. The Journal of Real Estate Finance and Economics, 34(1), 5-33.

Geltner, D. (2011). A simplified transactions based index (TBI) for NCREIF production. MIT Center for Real Estate \& Geltner Associates LLC. https://mitcre.mit.edu/wpcontent/uploads/2012/11/TBI_WhitePaper_ DG FINAL May2011.pdf.

Hall, R. E. (1978). Stochastic implications of the life cycle-permanent income hypothesis: Theory and evidence. The Journal of Political Economy, 86(6), 971-987.

Heinig, S., \& Nanda, A. (2018). Measuring sentiment in real estate - A comparison study. The Journal of Property Investment and Finance, 36(3), 248-258.

Heinig, S., Nanda, A., \& Tsolacos, S. (2020). Which sentiment indicators matter? evidence from the European commercial real estate market. The Journal of Real Estate Research. 42(4) 499-530. Available at https:// www.tandfonline.com/doi/full/10.1080/08965803.2020.1845562.

Hirshleifer, D. (2001). Investor psychology and asset pricing. The Journal of Finance, 56(4), 1533-1597.

Hohenstatt, R., \& Kaesbauer, M. (2014). GECO's weather forecast for the UK housingmarket: To what extent can we rely on Google econometrics? Journal of Real Estate Research, 36(2), 253-282.

Kumar, A., \& Lee, C. M. (2006). Retail investor sentiment and return comovements. The Journal of Finance, 61(5), 2451-2486.

Levin, A., Lin, C. F., \& Chu, C. S. J. (2002). Unit root tests in panel data: Asymptotic and finite-sample properties. The Journal of Econometrics, 108(1), 1-24.

Lin, Z., \& Vandell, K. D. (2007). Illiquidity and pricing biases in the real estate market. Real Estate Economics, 35(3), 291-330.

Ling, D. C. (2005). A random walk down main street: Can experts predict returns on commercial real estate? The Journal of Real Estate Research, 27(2), 137-154. 
Ling, D., Marcato, G., \& McAllister, P. (2009). The dynamics of asset prices, capital flows, and transaction activity in illiquid, informational inefficient, commercial real estate markets. The Journal of Real Estate Finance and Economics, 39(3), 359-383.

Ling, D. C., Naranjo, A., \& Scheick, B. (2014). Investor sentiment, limits to arbitrage and private market returns. Real Estate Economics, 42(3), 531-577.

Ling, D. C., Ooi, J. T., \& Le, T. T. (2015). Explaining house price dynamics: Isolating the role of nonfundamentals. The Journal of Money, Credit and Banking, 47(S1), 87-125.

Lizieri, C., Marcato, G., Ogden, P., \& Baum, A. (2012). Pricing inefficiencies in private real estate markets using total return swaps. The Journal of Real Estate Finance and Economics, 45(3), 774-803.

Marcato, G., \& Nanda, A. (2016). Information content and forecasting ability of sentiment indicators: Case of real estate market. The Journal of Real Estate Research, 38(2), 165-203.

McNamara, P. (1998). Exploring liquidity: Recent survey findings. In The 7th Investment Property Databank Conference (pp. 27-28) November.

Nanda, A. (2007). Examining the NAHB/Wells Fargo Housing Market Index (HMI). National Association of Home Builders, Washington, DC. March. https://www.nahbclassic.org/generic.aspx?genericContentID= $73820 \&$ fromGSA $=1$.

Sirmans, G. S., MacDonald, L., \& Macpherson, D. (2010). A meta-analysis of selling price and time-on-themarket. Journal of Housing Research, 19(2), 139-152.

van Dijk, D., Geltner, D., \& van de Minne, A. (2018). Revisiting supply and demand indexes in real estate. DNB Working Paper No. 583, January 2018. https://www.dnb.n1/media/mfdcuyr2/working-paper-no583 tcm47-371999.pdf.

Wooldridge, J. M. (2010). Econometric analysis of cross section and panel data. Cambridge: MIT Press.

Publisher's Note Springer Nature remains neutral with regard to jurisdictional claims in published maps and institutional affiliations. 